\title{
Preparation of different carbon materials by thermochemical conversion of lignin
}

\section{Juana M. Rosas, Raúl Berenguer, María José Valero-Romero, José Rodríguez-Mirasol and Tomás Cordero*}

Departamento de Ingeniería Química, Andalucía Tech, Universidad de Málaga, Málaga, Spain

Edited by:

Emilia Morallón, Universidad de Alicante, Spain

\section{Reviewed by:}

Diego Cazorla-Amorós, Universidad de Alicante, Spain

Soshi Shiraishi, Gunma University, Japan

*Correspondence:

Tomás Cordero, Departamento de

Ingeniería Química, Facultad de

Ciencias, Campus de Teatinos s/n,

Andalucía Tech, Universidad de

Málaga, Málaga 29071, Spain

e-mail:cordero@uma.es

\begin{abstract}
Lignin valorization plays a crucial role within the modern biorefinery scheme from both the economic and environmental points of view; and the structure and composition of lignin makes it an ideal precursor for the preparation of advanced carbon materials with high added-value. This review provides an overview of the different carbonaceous materials obtained by thermochemical conversion of lignin, such as activated carbons, carbon fibers, templated carbons, and high ordered carbons, giving information about the new strategies in terms of the preparation method and their possible applications.
\end{abstract}

Keywords: lignin, biomass, revalorization, activated carbons, fiber, template

\section{INTRODUCTION}

Lignin is one of the three basic components of wood and other lignocellulosics. Lignin is primarily a structural material to add strength and rigidity to cell walls and constitutes between 15 and $40 \mathrm{wt} \%$ of the dry matter of woody plants. Lignin may be considered to be a random three-dimensional polymer of phenylpropane units linked together in different ways (Figure 1).

Nowadays, lignin represents $30 \%$ of all non-fossil organic carbon on Earth. Its availability exceeds 300 billion tons (Smolarski, 2012), increasing annually by around 20 billion tons. The worldwide production of lignin is between 40 and 50 million tons per annum (The International Lignin Institute, ILI). Besides, most of the produced lignin is consumed as a fuel in the pulp-paper industry to recover energy and chemical reactant, and only the $2 \%$ is actually being commercialized.

There are different lignin sources depending on the biomass process, such as pulp and paper industries (i.e., Kraft or lignosulfonate) or new feedstocks specific to the biorefinery scheme (i.e., Organosolv). The most yielded lignin type is the so-called Kraft lignin, which comes from the Kraft pulping process. This is the main traditional method for pulping and hence, it produces the largest volume of lignin (Smook, 2002).

Other important types of lignin are derived from the organosolv process, which is a pulping technique that uses an organic solvent to solubilize lignin and hemicelluloses. In this case, the Alcell ${ }^{\circledR}$ process is the most well-known process in the organosolvlignin category. In contrast to Kraft lignin, Alcell ${ }^{\circledR}$ lignin contains very small amount of inorganic compounds because of the different pulping process used (Kubo and Kadla, 2004). Interestingly, the Alcell ${ }^{\circledR}$ pulping process exhibits higher pulp yields than the Kraft process and it is also more environmentally friendly (Yawalata and Paszner, 2004). The recovery of solvents by evaporation is easy and it allows obtaining a very pure lignin that can be used as a raw material.
In recent years, isolation of different forms of modified lignin from pulping black liquors and the development of further applications for them has gained a great interest because of the biorefinery process. In this context, lignin will be used as raw material for the preparation of chemicals and carbons materials. The integration of lignin in multi-component materials have been encouraged over the last 10 years by their wide accessibility, low price, and performances, such as low density, high hardness, good thermal properties, chemical, friction, and humidity resistance (Laurichesse and Avèrous, 2014).

The current commercial uses of lignin, except combustion and production of synthetic vanillin and dimethylsulfoxide (DMSO), make use of lignin's polymer and polyelectrolyte properties. Its use as dispersant, emulsifier, binder, and sequestrant supposes nearly three-quarters of the commercial lignin products. Other, minor applications include adhesives and fillers. Generally, lignin is used in these applications with little or no modification other than sulfonation or thio hydroxymethylation. These uses mainly represent relatively low value and limited volume growth applications.

Furthermore, large amounts of lignin could be generated in future wood-to-ethanol bio-refineries. Therefore, the development of value-added lignin-based products will be crucial to the economic success of the bio-ethanol production by this process.

In this sense, another potential way of lignin valorization is by thermochemical conversion in order to obtain carbon materials with high value added. During thermochemical conversions, a significant devolatilation may occur, with the loss of most of the oxygen functional groups. The reorganization of the structure, mainly by condensation of the aromatic rings, produces carbon materials.

This review is mainly focused on the preparation of advanced carbon materials by thermochemical processes of lignin. Figure 2 shows a scheme of the potential thermochemical conversion routes 
for lignin, which will be analyzed in this review. As can be seen by thermochemical processes from lignin, it can be prepared by activated carbons (ACs), carbon molecular sieves, high-ordered carbons, catalysts and catalyst supports, carbon fibers (CFs), and tubes and nanostructured carbon materials, also called templated carbons.

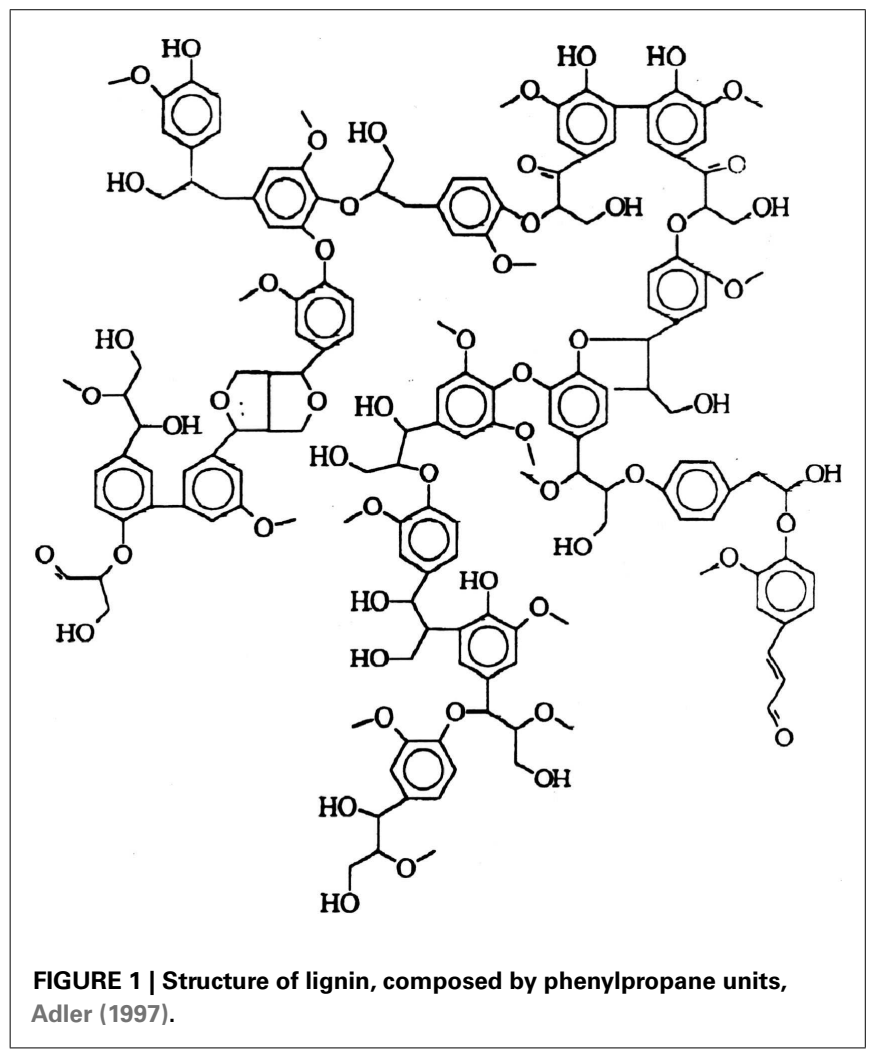

\section{ACTIVATED CARBONS}

As lignin has a high carbon content and a molecular structure similar to bituminous coal, it ought to be an ideal precursor for ACs (Suhas et al., 2007). ACs usually have a well-developed porous structure with a large internal surface area ranging from 500 to $2000 \mathrm{~m}^{2} / \mathrm{g}$, high thermal and chemical stability in both highly acidic and alkaline media and, in addition, the chemistry of the carbon surface can be easily modulated. Furthermore, they can be obtained from many diverse materials including different types of lignocellulosic waste (Rodríguez-Mirasol et al., 2005; Ioannidou and Zabaniotou, 2007; Rosas et al., 2009, 2010). All these properties make them very suitable materials as adsorbent and catalyst supports (Radovic and Rodríguez-Reinoso, 1997).

This section of the review tries to compile the main works related to ACs from lignin, analyzing the preparation methods, the properties of the resultant ACs, and the different applications of these materials, such as adsorbents, catalyst supports, or catalysts by themselves (when the authors provided this information). Table 1 provides information related to the type of activation, activation agent, kind of lignin, and the application evaluated in each case. For the sake of clarity, this section is structured as a function of the type of activation method.

\section{PHYSICAL ACTIVATION}

Physical activation is a two-step process that consists of the early formation of a char by pyrolysis (carbonization) of the precursor; and an activation step, where the char is partially gasified by different gases, such as $\mathrm{CO}_{2}$ or steam, producing a well-developed (micro)porous structure.

\section{Carbonization step}

The effect of carbonization temperature on the porosity development of chars was first analyzed by Rodríguez-Mirasol et al. (1993a,b) using Eucalyptus Kraft lignin. They reported a

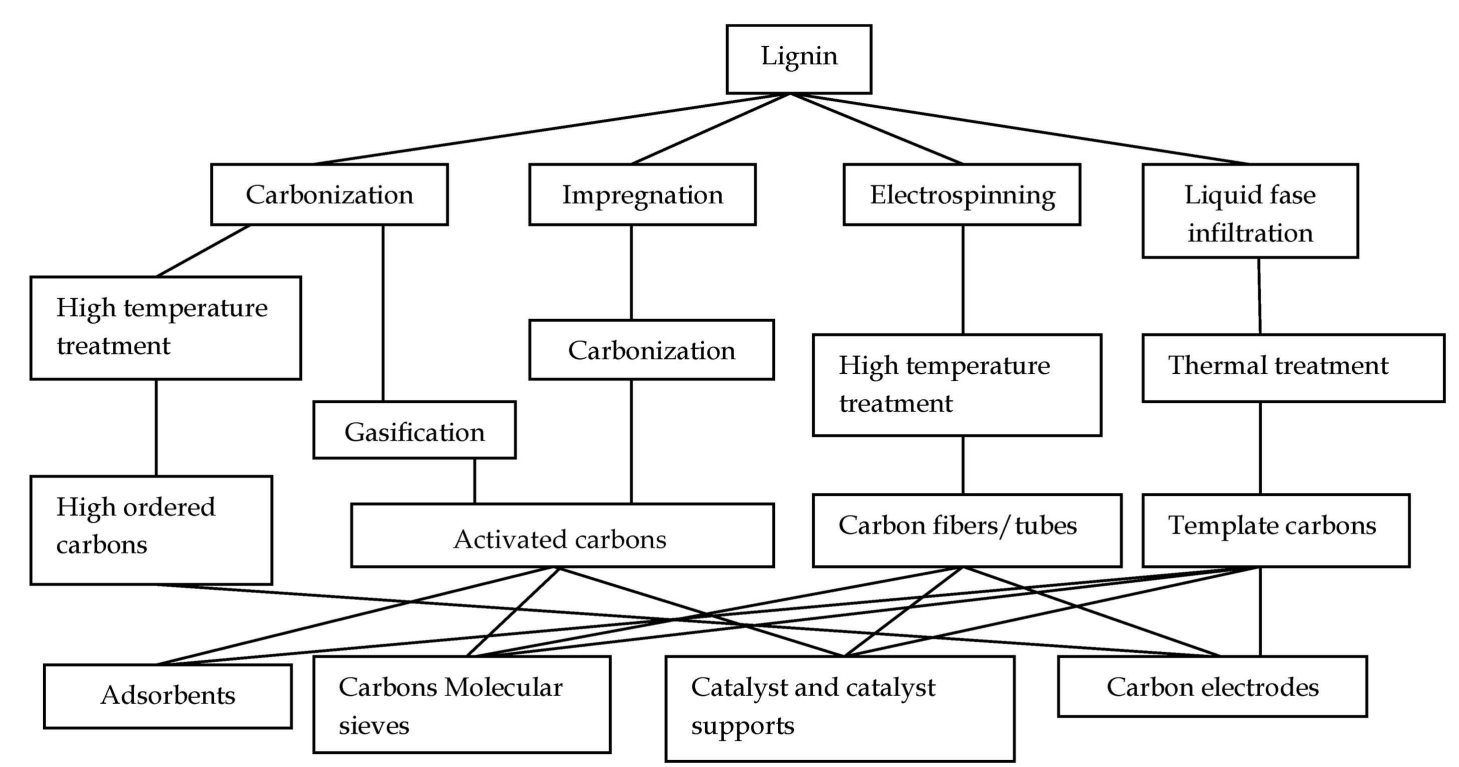

FIGURE 2 | Possible routes of lignin thermochemical conversion 
Table 1 | Experimental conditions, type of lignin, and application of activated carbons prepared from lignin (physical activation) and (chemical activation).

\begin{tabular}{|c|c|c|c|c|c|}
\hline Type of lignin & $\begin{array}{l}\text { Activation } \\
\text { agent }\end{array}$ & $\begin{array}{l}\text { Experimental } \\
\text { conditions }\end{array}$ & $A_{B E T}\left(m^{2} / g\right)$ & Application & Reference \\
\hline \multicolumn{6}{|c|}{ (A) PHYSICAL ACTIVATION } \\
\hline Eucalyptus Kraft lignin & $\mathrm{CO}_{2}$ & $800^{\circ} \mathrm{C}$ & $700-1900$ & $\begin{array}{l}\text { Adsorbent: water vapor, aromatic } \\
\text { compounds, surfactant, } \\
\text { dyes, etc. }\end{array}$ & $\begin{array}{l}\text { Bedia et al. (2007); Cotoruelo et al. } \\
\text { (2007a,b, 2009, 2010, 2011a,b, } \\
\text { 2012a,b); Rodríguez-Mirasol et al. } \\
\text { (2005) }\end{array}$ \\
\hline Hydrolytic lignin & $\mathrm{H}_{2} \mathrm{Ov}$ & $800^{\circ} \mathrm{C}, 2 \mathrm{~h}$ & 865 & $\begin{array}{l}\text { Molecular sieve: He from a } \\
\mathrm{He}-\mathrm{CH}_{4} \text { mixture }\end{array}$ & Baklanova et al. (2003) \\
\hline Kraft and hydrolytic lignin & $\mathrm{CO}_{2}$ and $\mathrm{H}_{2} \mathrm{O}_{v}$ & $750^{\circ} \mathrm{C}$ & $1400-1600$ & n.d. & Carrott et al. (2008) \\
\hline Black liquor lignin & $\mathrm{H}_{2} \mathrm{O}_{v}$ & $725^{\circ} \mathrm{C}, 40 \mathrm{~min}$ & 310 & Adsorbent: MB & Fu et al. (2013) \\
\hline Kraft lignin & $\mathrm{KOH}$ & $700^{\circ} \mathrm{C}, R=0.25$ & 514 & Adsorbent: phenol and MB & Khezami et al. (2005) \\
\hline Kraft lignin & $\mathrm{KOH}$ & $950^{\circ} \mathrm{C}, R=4$ & 1946 & Hydrogen electrosorption & Babel and Jurewicz (2008) \\
\hline Kraft lignin & $\mathrm{KOH}$ & $750^{\circ} \mathrm{C}, R=4$ & 2763 & n.d. & Li et al. (2014) \\
\hline Kraft lignin & $\mathrm{KOH}$ & $750^{\circ} \mathrm{C}, R=0.33$ & 2943 & Adsorbent: Ni(II) & Gao et al. (2013) \\
\hline Kraft lignin & $\begin{array}{l}\mathrm{KOH} \\
\mathrm{NaOH}\end{array}$ & $700^{\circ} \mathrm{C}, R=3$ & $\begin{array}{l}3000 \\
2400\end{array}$ & n.d. & Fierro et al. $(2007 a, b)$ \\
\hline Kraft lignin & $\mathrm{NaOH}$ & $755^{\circ} \mathrm{C}, R=5$ & 2400 & Adsorbent: MB & Torné-Fernández et al. (2009) \\
\hline Kraft lignin & $\mathrm{H}_{3} \mathrm{PO}_{4}$ & $500^{\circ} \mathrm{C}, R=2$ & 820 & $\begin{array}{l}\text { Molecular sieve: } \mathrm{CO}_{2}, \mathrm{CH}_{4} \\
\text { and } \mathrm{N}_{2}\end{array}$ & Sun et al. (2012) \\
\hline Kraft lignin & $\mathrm{H}_{3} \mathrm{PO}_{4}$ & $450^{\circ} \mathrm{C}, R=2.5$ & $\sim 1500$ & n.d. & Guo and Rockstraw (2006) \\
\hline Alcell lignin & $\mathrm{H}_{3} \mathrm{PO}_{4}$ & $500^{\circ} \mathrm{C}, R=3$ & 1099 & Catalyst: 2-propanol dehydration & Bedia et al. (2009) \\
\hline Alcell lignin & $\mathrm{H}_{3} \mathrm{PO}_{4}$ & $500^{\circ} \mathrm{C}, R=3$ & 1015 & Oxidation resistance & Rosas et al. (2012) \\
\hline Kraft lignin & $\mathrm{H}_{3} \mathrm{PO}_{4}$ & $500^{\circ} \mathrm{C}, R=3$ & $\sim 1500$ & $\begin{array}{l}\text { Catalyst support }(\mathrm{Pd}) \text { : } \\
\text { hydrogenation and Suzuki } \\
\text { reactions }\end{array}$ & Guillen et al. (2009) \\
\hline Kraft lignin & $\mathrm{H}_{3} \mathrm{PO}_{4}$ & $500^{\circ} \mathrm{C}, R=3$ & $\sim 1500$ & $\begin{array}{l}\text { Catalyst support }(\mathrm{Pd}) \text { : toluene } \\
\text { oxidation }\end{array}$ & Bedia et al. (2010) \\
\hline
\end{tabular}

maximum specific surface area $\left(A_{\mathrm{BET}}\right)$ value of $496 \mathrm{~m}^{2} / \mathrm{g}$ at $550^{\circ} \mathrm{C}$, decreasing to $278 \mathrm{~m}^{2} / \mathrm{g}$ at $900^{\circ} \mathrm{C}$. They associated this trend to the micropores constriction upon increasingly severe thermal treatment, reducing the accessibility of the $\mathrm{N}_{2}$ molecules in their experimental conditions. However, Xie et al. (2009) reported with organosolv-lignin powder, an increasing tendency in $A_{\mathrm{BET}}$ with temperature, reaching values of $449 \mathrm{~m}^{2} / \mathrm{g}$ at $1000^{\circ} \mathrm{C}$. In this case, the heating rate was $2.5^{\circ} \mathrm{C} / \mathrm{min}$, in contrast with that used by Rodriguez-Mirasol et al., $10^{\circ} \mathrm{C} / \mathrm{min}$. In this sense, Kijima et al. (2011) analyzed the effect of the heating rate on an alkaline lignin 
carbonized at $900^{\circ} \mathrm{C}$, and they observed that the lower the heating rate, the higher the $A_{\mathrm{BET}}$. They obtained a char at $1^{\circ} \mathrm{C} / \mathrm{min}$, with $530 \mathrm{~m}^{2} / \mathrm{g}$, which was increased to $740 \mathrm{~m}^{2} / \mathrm{g}$ after washing with water.

Although in the scheme shown in Figure 2, it appears as a separate block, to our best knowledge, only Rodríguez-Mirasol et al. (1996) made high temperature treatments to powder lignin with the goal of obtaining high-ordered carbons, so the preparation of this kind of materials is not going to be considered as a separate part within the review.

In that case, these ordered carbons were obtained from Kraft lignin, under Ar flow, at temperatures in the range between 2400 and $2800^{\circ} \mathrm{C}$. The structural order of the carbons was progressively increasing with the temperature, as revealed by XRD and Raman spectroscopy analyses, at the same way than their oxidation resistance. The inorganic impurities of the precursor (mainly $\mathrm{Na}$ ) seemed to enhance the onset of structural ordering, and the oxidation resistance of the $2800^{\circ} \mathrm{C}$ carbon prepared from high-ash lignin proved to be similar to that of graphite SP-1.

\section{Activation step}

The most used activating gas during the activation step is $\mathrm{CO}_{2}$. Rodríguez-Mirasol et al. (1993a,b) obtained an AC with $1853 \mathrm{~m}^{2} / \mathrm{g}$ and a micropore volume $\left(V_{\text {mic }}\right)$ of $0.57 \mathrm{~cm}^{3} / \mathrm{g}$, at $850^{\circ} \mathrm{C}$, for $20 \mathrm{~h}$, in $\mathrm{CO}_{2}$. This high activation time provided information about the low reactivity of lignin chars, owing to its highly cross-linked nature, later confirmed by Sharma et al. (2004).

More recently, Baklanova et al. (2003) analyzed the influence of the carbonization temperature with hydrolytic lignin. They optimized the experimental conditions to prepare microporous ACs, and they observed that carbonization temperatures of $600-700^{\circ} \mathrm{C}$ could be used for producing microporous char materials with a minimum average size of micropores. In addition, they obtained ACs with $865 \mathrm{~m}^{2} / \mathrm{g}$ and $V_{\text {mic }}$ of $0.37 \mathrm{~cm}^{3} / \mathrm{g}$, with an average width $\left(\bar{r}_{\text {mic }}\right)$ of $0.60-0.66 \mathrm{~nm}$, by steam activation of the carbonized samples produced.

Carrott et al. (2008) analyzed the physical activation in $\mathrm{CO}_{2}$ or steam of kraft and hydrolytic lignins. They observed that lignins obtained from different sources behave differently during pyrolysis and also during activation in $\mathrm{CO}_{2}$ or steam, leading to the formation of ACs with different textural properties, better in the case of hydrolytic lignin. The most porous materials had $A_{\mathrm{BET}}$ between 1400 and $1600 \mathrm{~m}^{2} / \mathrm{g}$ with $V_{\text {mic }}$ between 0.5 and $0.6 \mathrm{~cm}^{3} / \mathrm{g}$ and $\bar{r}_{\text {mic }}$ between 1.2 and $1.4 \mathrm{~nm}$.

More recently, Fu et al. (2013) prepared ACs directly from black liquor lignin by physical activation with steam, with a maximum $A_{\mathrm{BET}}$ of $310 \mathrm{~m}^{2} / \mathrm{g}$. at $725^{\circ} \mathrm{C}$ for $40 \mathrm{~min}$. Higher activation times and temperatures significantly reduced the specific surface area. These ACs were tested as adsorbents for methylene blue (MB).

On the other hand, it is important to mention the works of our research group in this field. Based on the earlier studies of Rodríguez-Mirasol et al. (1993a,b), our research group has continued searching applications for the ACs obtained from Eucalyptus kraft lignin by physical activation with $\mathrm{CO}_{2}$. Specifically, the viability of these ACs to be used as adsorbents in liquid phase has been analyzed by developing adsorbent materials with different properties, in order to achieve selective applications, depending on the molecules to be separated. In this sense, ACs with very different porous structure, with $A_{\mathrm{BET}}$ ranging from approximately 700 to $1900 \mathrm{~m}^{2} / \mathrm{g}$ have been tested. The suitability of these ACs has been analyzed for the removal of aromatic compounds (benzene, methyl ethyl ketone, methanol, nitrobenzene, aniline, $\mathrm{p}$ nitroaniline, toluene, and p-nitrotoluene), surfactants (sodium dodecylbenzene sulfonate), dyes (Congo Red, crystal violet, fuchsine and malachite green), and intermediates or final products in petrochemical, pharmaceutical and food industries (paracetamol, salicylic acid and benzoic acid) (Rodríguez-Mirasol et al., 2005; Cotoruelo et al., 2007b, 2009, 2010, 2011a,b, 2012a,b). These ACs were successfully employed as adsorbents for the removal of these components, analyzing the influence of $\mathrm{pH}$, temperature, and contact time and making a deep study of the thermodynamic and kinetic of the adsorption process. In this context, Bedia et al. (2007), based on the high amount of $\mathrm{Na}$ observed in kraft lignin, used these ACs for desiccant applications. To our best knowledge, there is no information about the use of ACs, obtained by physical activation from lignin, as catalyst supports or catalysts by themselves.

\section{CHEMICAL ACTIVATION}

\section{$\mathrm{ZnCl}_{2}$ as activation agent}

Gonzalez-Serrano et al. (1997) were pioneers to prepare ACs from lignin precipitated from kraft black liquors by using chemical activation, in this case, with $\mathrm{ZnCl}_{2}$. The authors reported ACs with $A_{\text {BET }}$ higher than $1800 \mathrm{~m}^{2} / \mathrm{g}$. They observed that activation temperatures up to $500^{\circ} \mathrm{C}$ and high impregnation ratios ( $R=$ mass activation agent/mass lignin), up to 2.3, leads to well-developed porosity with a widening of microporosity and an increasing contribution of mesoporosity, recommended for liquid-phase applications.

Later, Hayashi et al. (2000), also with Kraft lignin, found that the maximum $A_{\mathrm{BET}}$ were obtained at the activation temperature of $600^{\circ} \mathrm{C}$, with $R=1$. On the other hand, Maldhure and Ekhe (2011) compared the use of a microwave technique to conventional impregnation method, using Kraft lignin, at $R=1.5$ and $600^{\circ} \mathrm{C}$. They obtained an overall beneficial effect in terms of porous structure, relatively greater surface area, reduction of time, and energy toward effectiveness of impregnation, with microwave method. Furthermore, the ACs prepared by microwave treatment showed higher capacity for $\mathrm{Cu}(\mathrm{II})$ adsorption compared to ACs prepared by the simple method.

\section{Alkali metal compounds as activation agent}

Hayashi et al. (2000) also tested for the activation of lignin, different alkali metal compounds, such as $\mathrm{NaOH}, \mathrm{KOH}, \mathrm{Na}_{2} \mathrm{CO}_{3}$, and $\mathrm{K}_{2} \mathrm{CO}_{3}$, with $R=1$. In that case, the optimum carbonization temperature was $800^{\circ} \mathrm{C}$, obtaining $A_{\mathrm{BET}}$ higher than $1000 \mathrm{~m}^{2} / \mathrm{g}$, except for $\mathrm{Na}_{2} \mathrm{CO}_{3}$. In particular, the carbon prepared by $\mathrm{K}_{2} \mathrm{CO}_{3}$ activation has a $A_{\mathrm{BET}}$ of $2000 \mathrm{~m}^{2} / \mathrm{g}$.

Khezami et al. (2005) compared the activation with $\mathrm{KOH}$ of different wood components (cellulose, lignin, and xylan) and they obtained an AC from lignin of $514 \mathrm{~m}^{2} / \mathrm{g}$, at $700^{\circ} \mathrm{C}$ and $R=0.25$. They also tested the adsorption capacity of the ACs prepared for MB and phenol. On the other hand, Babel and Jurewicz (2008) prepared nanostructured carbons by $\mathrm{KOH}$ activation of lignin 
(from black liquid of pine wood pulping process) at $950^{\circ} \mathrm{C}$ and $R=4$. The AC showed an $A_{\mathrm{BET}}$ of $1946 \mathrm{~m}^{2} / \mathrm{g}$, with a considerable number of supermicropores and small mesopores (ca., $50 \%$ ). This AC obtained an efficient hydrogen electrosorption of $510 \mathrm{~mA} \mathrm{~h} / \mathrm{g}$ (1.89 wt $\%$ in meaning of energy storage) and favorable discharge characteristics at current densities up to $1 \mathrm{~A} / \mathrm{g}$.

Torné-Fernández et al. (2009) synthesized highly microporous carbon materials with high $A_{\mathrm{BET}}$ (up to $2400 \mathrm{~m}^{2} / \mathrm{g}$ ) from Kraft lignin by activation with $\mathrm{NaOH}$. The optimal conditions were $755^{\circ} \mathrm{C}$ and approximately $R=5$. This $\mathrm{AC}$ was tested for $\mathrm{MB}$ adsorption with successful results.

Due to $\mathrm{K}_{2} \mathrm{CO}_{3}$ salts had shown high transesterification activities when are supported on different materials, Li et al. (2013) prepared and AC from Kraft lignin by chemical activation with $\mathrm{K}_{2} \mathrm{CO}_{3}$, at $800^{\circ} \mathrm{C}$ and $R=0.6$. This $\mathrm{AC}$ was used as solid base catalyst for biodiesel production. The catalyst, with a potassium element content estimated by XPS of $18 \mathrm{wt} \%$ and $A_{\mathrm{BET}}$ of $41 \mathrm{~m}^{2} / \mathrm{g}$, was evaluated by transesterification of rapeseed oil with methanol, obtaining a biodiesel yield of $99.6 \%$. Furthermore, the catalyst was effectively reused four times, with almost the same activity.

Low-cost AC with high surface area was also prepared from lignin of papermaking black liquor by $\mathrm{KOH}$ activation. Fierro et al. (2007a) obtained by the traditional method, an AC with very high $A_{\mathrm{BET}}, 3000 \mathrm{~m}^{2} / \mathrm{g}$, and $V_{\text {mic }}$ of $1.5 \mathrm{~cm}^{3} / \mathrm{g}$, at $700^{\circ} \mathrm{C}$ (for $1 \mathrm{~h}$ ) and $R=3$. The same authors also made a comparison between $\mathrm{KOH}$ and $\mathrm{NaOH}$ and they found that, whatever the preparation conditions, $\mathrm{KOH}$ led to the most microporous materials, having surface areas and micropore volumes typically 1.5 and 1.2 times higher than those obtained with $\mathrm{NaOH}$ (Fierro et al., 2007b). Li et al. (2014) obtained very similar results, with an AC with $2763 \mathrm{~m}^{2} / \mathrm{g}$, at $R=4$, an activation temperature of $750^{\circ} \mathrm{C}$ and an activation time of $2 \mathrm{~h}$. However, the procedure was slightly different in case of Gao et al. (2013), because the activation step was preceded by a pre-carbonization treatment. These authors obtained, in this case, an AC with a high $A_{\mathrm{BET}}$ up to $2943 \mathrm{~m}^{2} / \mathrm{g}$. But the results, here, were quite different because the maximum surface area was obtained at $R=0.33$, activation temperature of $750^{\circ} \mathrm{C}$ and activation time of $1 \mathrm{~h}$. This AC was used as adsorbent for Ni (II) removal from aqueous phase.

\section{$\mathrm{H}_{3} \mathrm{PO}_{4}$ as activation agent}

Hayashi et al. (2000, 2002) also studied the activation of Kraft lignin with $\mathrm{H}_{3} \mathrm{PO}_{4}$. They observed a maximum development of the porous structure, with $A_{\mathrm{BET}}$ round $1000 \mathrm{~m}^{2} / \mathrm{g}$, at an activation temperature of $600^{\circ} \mathrm{C}$, although they only optimized the temperature at $R=1$. Gonzalez-Serrano et al. (2004) also used $\mathrm{H}_{3} \mathrm{PO}_{4}$ as activating agent, at impregnation ratios between 1 and 3 , and activation temperatures between 350 and $600^{\circ} \mathrm{C}$. They provided an optimum of $R=2$, and an activation temperature around $427^{\circ} \mathrm{C}$, as the best combination of operating conditions to prepare ACs for aqueous phase applications. Specifically, they tested these carbons with relevant results for the removal of phenol, 2,4,5-trichlorophenol and Cr (VI) as representative of toxic contaminants found in industrial wastewaters.

On the other hand, Montane et al. (2005) made an interesting research on the activation of Kraft lignin with $\mathrm{H}_{3} \mathrm{PO}_{4}$. They have developed a phenomenological kinetic model (Montane et al.,
2005). They also optimized the preparation condition of AC from Kraft lignin with $\mathrm{H}_{3} \mathrm{PO}_{4}$ by modifying the activation temperature $\left(400-650^{\circ} \mathrm{C}\right)$, the impregnation ratios $(0.7-1.75)$ and impregnation times (1-48 h) (Fierro et al., 2006). They obtained a maximum $A_{\text {BET }}\left(1305 \mathrm{~m}^{2} / \mathrm{g}\right)$ and pore volume $\left(0.67 \mathrm{~cm}^{3} / \mathrm{g}\right)$ at $600^{\circ} \mathrm{C}$. They also pointed out that the effect of impregnation time is more important at high carbonization temperatures due to decomposition of phosphate and polyphosphate bridges cross-linking parts of the carbon structure. In this sense, Fierro et al. (2007c) also analyzed the effect of Kraft lignin demineralization and they found that demineralization process produced lignin polymerization and reduced its ability to react with $\mathrm{H}_{3} \mathrm{PO}_{4}$. Furthermore, demineralized Kraft lignin provided ACs with lower adsorption capacities for $\mathrm{MB}$, probably due to the lower ash and sulfur contents.

On the other hand, and being more related to the potential applications of these materials, Sun et al. (2012) used an AC prepared from lignin by $\mathrm{H}_{3} \mathrm{PO}_{4}$ activation, at $500^{\circ} \mathrm{C}$ and $\mathrm{R}=2$, as molecular sieve. However, despite the AC provided a satisfactory representation of high pressure $\mathrm{CO}_{2}, \mathrm{CH}_{4}$, and $\mathrm{N}_{2}$ adsorption, the separation kinetic between $\mathrm{CO}_{2}$ and $\mathrm{CH}_{4}$ was quite limited.

Less effort has been related to study the surface chemistry of ACs from lignin prepared by this method. In this sense, Guo and Rockstraw (2006) prepared carbons from xylan, cellulose, and Kraft lignin by $\mathrm{H}_{3} \mathrm{PO}_{4}$ activation. They observed the formation of two different acidic surface groups, such as carboxylic-containing groups of varying acidic strength, and phosphorus-containing groups. They also observed slightly larger amounts of these last groups by using Kraft lignin as precursor.

Specifically in our research group, it has been carried out a deep research of the surface chemistry and the possible catalytic applications of the carbons obtained by chemical activation with phosphoric acid. These carbons present a developed porous structure and also high surface acidity as a consequence of the oxygen-phosphorus groups formed on the carbon surface during the activation process (Rosas et al., 2008, 2009; Bedia et al., 2009). The XPS P2p (Figure 3) results seem to indicate the presence of C-O-P and C-P-O groups on the surface of the ACs. C-O-P and $\mathrm{C}-\mathrm{P}-\mathrm{O}$ is representative of the possible groups formed during the chemical activation and thermal treatment (Table 2). The $\mathrm{H}$

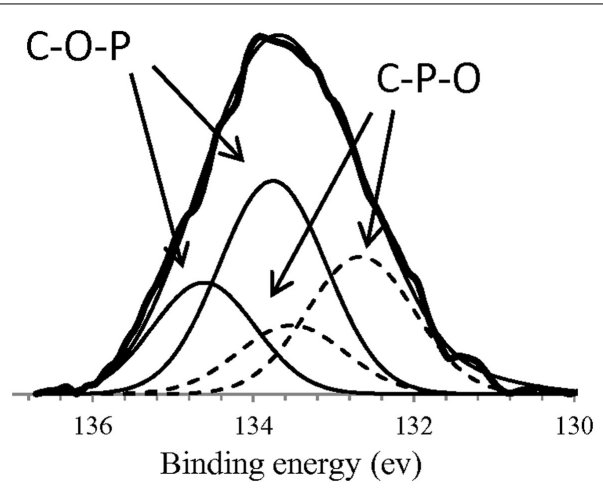

FIGURE 3 | XPS P 2p region for an activated carbons obtained by $\mathrm{H}_{3} \mathrm{PO}_{4}$ chemical activation of Alcell( $\mathrm{R}$ ) lignin with an impregnation ratio of 3 ( $w \mathrm{H}_{3} \mathrm{PO}_{4} /$ wt lignin). 
Table 2 | Possible phosphorus surface groups formed during $\mathrm{H}_{3} \mathrm{PO}_{4}$ activation, as C-O-P and C-P-O groups.

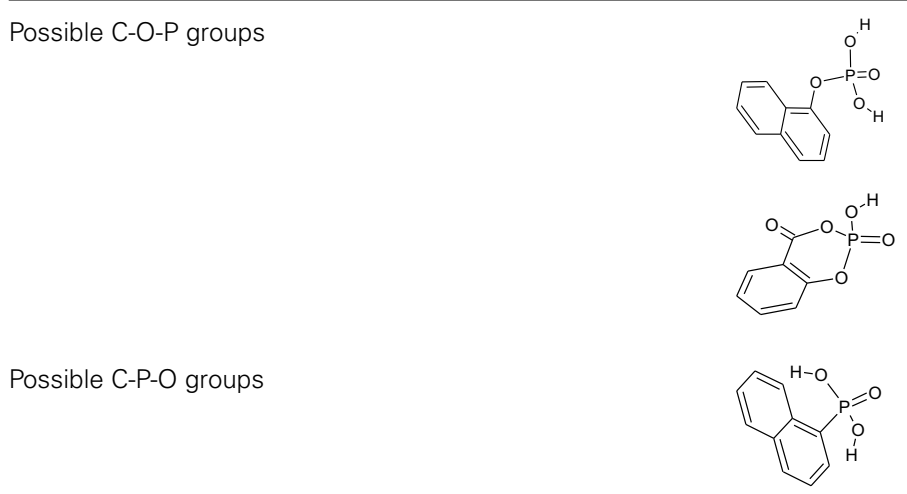

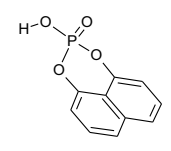
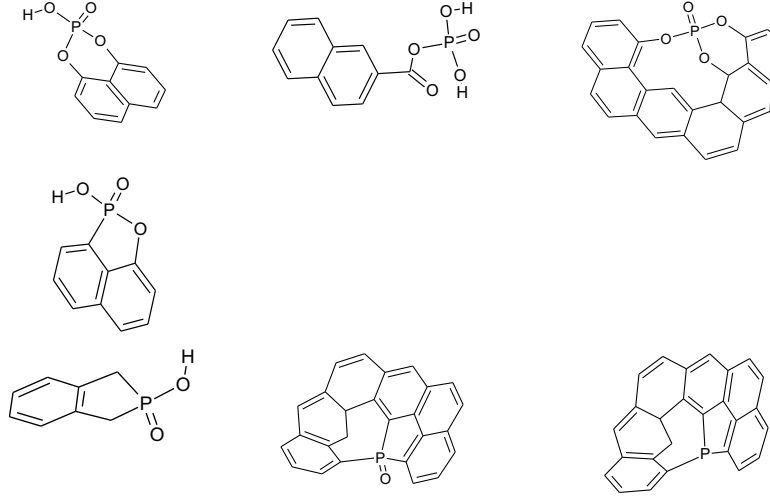

present in these groups provides the AC an acid character, stable at high temperature. Furthermore, these acidic groups present highthermal stability decomposing at temperatures higher than $700^{\circ} \mathrm{C}$. Taking advantage of these properties, Bedia et al. (2009) used an AC obtained from Alcell lignin as an acid catalyst for the dehydration of 2-propanol. The carbon acid catalysts were prepared by chemical activation with $\mathrm{H}_{3} \mathrm{PO}_{4}$, without the need of incorporating acid surface groups in a complementary step by chemical oxidation of the carbon surface. The conversions of 2-propanol yielded only dehydration products, mainly propylene, with very low amounts of di-isopropyl ether, confirming the acidic nature of the catalyst sites. Furthermore, the presence of water vapor did not affect significantly the conversion and the product distribution, what constitutes an important advantage with respect to some inorganic catalysts.

The aforementioned phosphorus surface complexes, in the form of $\mathrm{COPO}_{3}, \mathrm{CPO}_{3}$ groups, which remain very stable at relatively high temperatures confer to carbons a high oxidation resistance (Wu and Radovic, 2006; Rosas et al., 2009, 2012). We have recently reported a detailed study on the oxidation resistance of these phosphorus-containing ACs obtained among others materials, from Alcell lignin (Rosas et al., 2012). This oxidation resistance is related to the inhibition effect of the phosphorus complexes. This high oxidation resistance opens new possibilities for the use of carbon-based materials as catalyst supports, for metals or metal oxides, for reactions that take place under oxidizing conditions at relatively high temperatures.

In this sense, mesoporous ACs were obtained by chemical activation of kraft lignin with $\mathrm{H}_{3} \mathrm{PO}_{4}$ and used as supports for the preparation of carbon-based Pd catalysts with low palladium content $(0.5 \%)$. Because of the high oxidation resistance of this carbon support, the catalyst was evaluated in the catalytic oxidation of toluene in the temperature range of $150-400^{\circ} \mathrm{C}$, obtaining a complete oxidation of toluene to $\mathrm{CO}_{2}$ and $\mathrm{H}_{2} \mathrm{O}$, without significant support gasification (Bedia et al., 2010). On the other hand, this catalyst was also tested for hydrogenation and Suzuki reactions. The presence of phosphorus groups on the carbon surface, especially $\mathrm{C}_{3} \mathrm{P}$ groups, avoids the need of using triphenylphosphine as ligand in the Suzuki-Miyaura reactions (Guillen et al., 2009). For both reactions, the catalyst shows high activity and selectivity, as well as high stability and reproducibility.

\section{LIGNIN-BASED CARBON FIBERS}

Considering the great technological and industrial importance of CFs, and the high price, scarcity, and growing consume/demand of their conventional fossil precursors (PAN and pitches), the manufacture of low-cost CFs with high added-value from a renewable, abundant, and cheap precursor like lignin is one of its most interesting and promising valorization routes, from both the economic and environmental points of view (Leitten et al., 2002; Lallave et al., 2007; Ruiz-Rosas et al., 2010; Frank et al., 2014; Ragauskas et al., 2014). The usage interest includes both the so-called highperformance CFs, showing excellent mechanical properties for structural applications (advanced composite materials, aerospace, military, sporting and luxury goods, etc.), and the general-purpose CFs for functional applications (adsorption, catalysis, energy storage and conversion, etc.) in which other properties, such as a high surface area and/or a suitable porosity, surface chemistry, electrical conductivity, and oxidation resistance are considered more important than the mechanical ones.

Apart from availability and low cost, the usage of lignin as a source of CFs brings about many other advantages. Its high carbon content $(\geq 60 \%)$ and efficiency for thermal conversion into carbon materials results in potentially high carbon yields. Compared to conventional PAN and pitch precursors, its higher solubility in volatile solvents avoids the evolution of toxic products (HCN or nitrous gases) during carbonization, and makes cheaper the overall manufacture because the lower cost of both the volatile solvents and their recovery processes, and, on the other hand, its higher inherent oxygen content enables a potentially much faster oxidative thermostabilization and, consequently, conversion into CFs.

In general (simplified) terms, the conventional manufacture of CFs from a given isolated industrial lignin mainly involves five successive processing steps: (i) purification and/or modification to obtain derived lignins with more suitable properties for their subsequent processing and/or optimization of the CF final properties; (ii) spinning into lignin fibers; (iii) oxidative thermostabilization of as-spun lignin fibers (most usually, in air, up to $200-250^{\circ} \mathrm{C}$ ) to avoid their fusion during (iv) the carbonization treatment at high temperatures under inert atmosphere $\left(500-1000^{\circ} \mathrm{C}\right)$ to produce lignin-based CFs; and finally, (v) a post-treatment to adjust/optimize their properties for structural 
(usually graphitization at temperatures above $1200^{\circ} \mathrm{C}$ ) or functional (mainly by physical activation and/or functionalization) applications (Figure 4).

In spite of the advantages of using lignin as precursor, the obtained fibrous carbon materials have not exhibited the needed properties to involve enough or comparable high value. As a consequence, most research in lignin-based CFs is being currently focused on these three aspects: (i) the optimization of lignin derivation and spinning for lignin fibers manufacture; (ii) the development of faster thermostabilization routes; and/or (iii) the achievement of CFs with new or enhanced properties for structural and functional applications.

\section{MANUFACTURE OF LIGNIN FIBERS: DIFFERENT LIGNINS AND SPINNING METHODS}

Similar to other polymers, the manufacture cost and the final morphology and properties of lignin-based CFs depend not only on carbon precursor chemistry and extraction technique but also on the fiber processing methodology. Thus, much research has been focused on the spinnability of several lignins in different fiber processing methods (mainly wet-, dry-, melt-, and electrospinning).

The manufacture of CFs from lignin has been known since the mid-60s, when various methods of forming fibers (wet-, dry-, and melt-spinning) from various lignins and by using additives and/or post-treatments, and their conversion to $\mathrm{CF}$, graphitized $\mathrm{CF}$, and activated CF were described (Otani et al., 1969).

\section{Dry- and wet-spinning}

After this pioneer work, the preparation of lignin-based CFs by wet- and dry-spinning processes dominated in the following decade. Both methods require soluble lignins, which were simpler to achieve and process at that time. Headed by Nippon Kayaku Company, lignin-based CFs prepared by dry-spinning of alkaline lignosulfonate/polyvinyl alcohol (PVA) solutions were studied and even commercialized (as Kayacarbon) at small scale (Fukuoka, 1969; Mikawa, 1970). Since infusible lignin was used and thermostabilization was not required, higher carbon yields were obtained through a more cost-efficient process. Nevertheless, and although various related patents and papers have been published until now, the research activity of lignin-based CFs through these methods, almost ceased in the 1980s. Some interesting examples are the co-spinning of lignin sulfonates with low amounts (up to $5 \mathrm{wt} \%$ ) of polyethylene oxide (PEO) or poly(acrylamide), predominantly by dry-spinning (Mansmann, 1974); and the various publications on the manufacture of CFs from lignin-PAN blends by wet-spinning (Bissett and Herriott, 2012; Seydibeyoglu, 2012).

\section{Melt spinning}

Among the different technologies for the production of ligninbased CFs, melt-spinning has been the most studied. The method is based on the extrusion of molten (fusible) lignin under inert atmosphere, so no solvents are needed and more homogeneous lignin fibers are obtained from the liquid state. However, the heterogeneous and partially oxidized nature of lignin demands a critical control of the melt-spinning step, so that, isolated lignin usually has to be purified, plasticized with additives and/or chemically modified to show suitable spinnability.

The objective is to prepare lignin with a low enough softening temperature $\left(T_{\mathrm{s}}\right)$, to avoid polymerization and/or cross-linking during extrusion, but with a high enough glass transition temperature $\left(T_{\mathrm{g}}\right)$ for economically acceptable stabilization rates. Thus, a narrow range of temperatures exists for manufacturing ligninbased CFs via melt extrusion. Hence, most research works have been focused on new strategies to obtain lignin that are suitable for melt-spinning and, at the same time, can be quickly and effectively thermostabilized to give rise to optimum mechanical properties.

The use of raw isolated lignin. The preparation of lignin-based CFs via melt-spinning started to be developed at the end of 1980 s. Sudo and Shimizu (1987) described the preparation of CFs from lignin obtained by the high pressure steam treatment of wood. Nevertheless, because of conceptual ease and availability, the adaptation of most conventional pulping processes to obtain spinnable lignin was then the preferred strategy. The first studies arrived from Uraki et al. $(1995,2001)$, who reported the preparation of

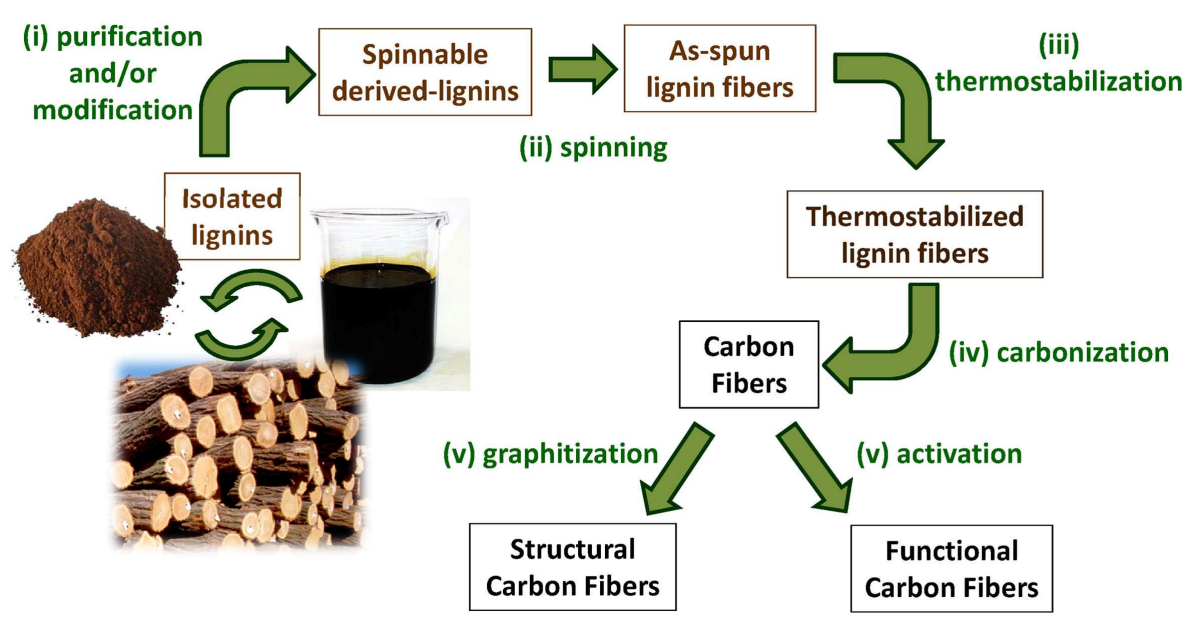

FIGURE 4 | Simplified scheme of lignin-based CF manufacture 
CFs from lignin recovered by the acetic-acid-catalyzed fractionation (Organosolv pulping) of wood. After solvent isolation, a direct melt-spinning process was enabled because of the partial acetylation of some of the lignin hydroxyl groups during pulping. The same authors further studied and compared the fusibility of softwood and hardwood acetic-acid lignin. Hardwood lignin (HAL) showed sufficient fusibility for melt-spinning, because of the partial acetylation during the pulping process, whereas softwood organosolv-lignin (SAL) could be converted into a fusible material by removing the infusible fraction. However, the authors did not succeed in converting softwood kraft lignin (SKL) into a fusible material (Kubo et al., 1998). Since then, other lignins recovered from other extraction methods have been investigated as precursor for CF production (Luo et al., 2011; Lin et al., 2012).

Great improvements were achieved by thermal or purification pre-treatments of isolated lignin to control the overall synthesis and properties of lignin-based CFs. Particularly, a thermal pretreatment under vacuum $\left(145^{\circ} \mathrm{C}\right.$ for $\left.1 \mathrm{~h}\right)$ was first used by Kadla et al. (2002a) to successfully melt-spin two commercially available (Alcell and Kraft) HALs for CF production. On the other hand, Baker et al. (2008a) proposed the purification of lignins by extraction with organic solvents, as a way to improve their spinnability and reduce their melting temperature. However, lower spinning temperatures necessarily led to the use of lower thermostabilization rates to prevent fusion upon carbonization. Furthermore, the same authors combined thermal and purification pre-treatments to obtain lignins with a narrow molecular weight distribution, suitable for multifilament melt-spinning (Baker and Gallego, 2010), or to enable the melt-spinning of a non-meltspinnable lignin like SKL (Baker et al., 2012). Since then, other purification treatments of lignin, like that of lignoboost process (Tomani, 2010), or its advanced version by membrane ultrafiltration (Nordström et al., 2012), have been more recently explored for the manufacture of CFs.

Blending with plasticizing additives. The utilization of plasticizing additives to improve the spinnability of lignins has been extensively reported on the literature. In the case of melt-spinning, the pioneers were Kadla and co-workers, who investigated the interactions and spinnability of lignin with PEO, poly(ethylene) (PE), poly(propylene) (PP), poly(ethylene terephthalate) (PET), and PVA. Due to their high miscibility with lignin, PEO and PET were found among the best additives in terms of spinnability and thermal properties. Practically, the role of these additives is to reduce the high softening temperature of some lignins, in order to make them spinnable. For instance, up to a $45^{\circ} \mathrm{C}$, a decrease in spinning temperature of commercially available HALs (HKL and HOL) was observed by blending with 5-25 wt\% PEO (Kadla et al., 2002a), and a non-spinnable lignin (SKL) was successfully processed into fibers after blending with $50 \mathrm{wt} \%$ PEO (Kubo and Kadla, 2004, 2005a). On the other hand, the non-polar character of PE and PP makes them immiscible with lignin, so that, the spinning of homogeneous blends to prepare structural CFs was not possible (Kadla et al., 2002b). In the case of lignin/PVA, the research has been focused on using lignin as a plasticizer to improve the processability of PVA fibers (Kubo and Kadla, 2003). Another promising approach has been the use of fusible (low $T_{\mathrm{g}}$ )
HALs as plasticizer of infusible (high $T_{\mathrm{g}}$ ) softwood lignins (Baker et al., 2008b; Warren, 2008; Nordström et al., 2012).

The obtainment of novel lignins by chemical modifications. The chemical modification of isolated lignins is also considered an interesting approach for CF manufacture. Some of the studied routes are hydrogenolysis, phenolysis, acetylation, derivatization, and copolymerization, among others. In the pioneer works by Sudo and Shimizu (1992), steam-exploded lignin was hydrogenated by using a Raney Ni catalyst, causing a significant elimination of aliphatic functional groups by cleavage of alkyl-aryl ether bonds and the formation of ethylene bridges between aromatic rings, to lower its softening point to improve melt-spinning. On the other hand, the authors also tested melt-spinnable phenolated lignins produced by different processes (Sudo et al., 1993; Sudo and Shimizu, 1994). Furthermore, demethoxylation (Gould, 1974) and acetylation (Eckert and Abdullah, 2008) were proved.

Another approach has been the chemical derivatization of lignins through their free hydroxyl groups to give plasticizing derivatives attached via ester, ether, and/or urethane functions (Wohlmann et al., 2010). Particular cases of derivatization have been the co-polimerization of lignins with other monomers and polymers, for example, by reaction of the guaiacyl groups of lignin with the formaldehyde groups to form lignin-phenolformaldehyde (LPF) resins (Shen et al., 2011), and by butyration with poly(lactic acid) (PLA) to form ester functional groups with lignin hydroxyl groups (Thunga et al., 2014), respectively, or the extension of lignin chains by different reactions, like propargylation derivatization of relatively lower molecular weight lignin followed by oxidative coupling reaction or thermal polymerization via the Claisen rearrangement (Sen et al., 2013).

\section{Electrospinning}

Electrospinning has emerged in recent years as a promising route for the preparation of novel lignin-based fibrous materials. Nevertheless, despite the benefits provided by the use of electrospinning and a cheap precursor like lignin, to date, there are relatively few published reports on the preparation of electrospun lignin fibers.

The research group of professor Cordero succeeded in applying this technique to the manufacture of pure lignin fibers (at room temperature and without chemical modifications or any added polymer), and also with different shapes, like solid pure and metal-supported or hollow lignin fibers (Lallave et al., 2007; Ruiz-Rosas et al., 2010). Highly concentrated ethanol solutions of as-received Alcell lignin were used in the co-axial and tri-axial configurations, respectively (Figure 5) (Loscertales et al., 2002, 2004). The incorporation of a Pt salt in the lignin:ethanol solution enabled the preparation of Pt-doped lignin fibers, while pumping glycerin, like sacrificial template, through the inner spinneret of a tri-axial configuration led to the preparation of glycerin-lignin core-shell co-axial fibers. After suitable thermostabilization and carbonization steps, the new straightforward method allowed the preparation of $200 \mathrm{~nm}$ to $2 \mu \mathrm{m}$ diameter electrospun solid CFs and Pt-containing CFs, see Figures 6A,B with a $0.3-0.6 \mathrm{wt} \%$ of well-dispersed Pt particles of around $10 \mathrm{~nm}$, or electrospun hollow CFs.

Apart from these results, lignin solutions (including organosolv, kraft, pyrolytic) have been found to display poor 

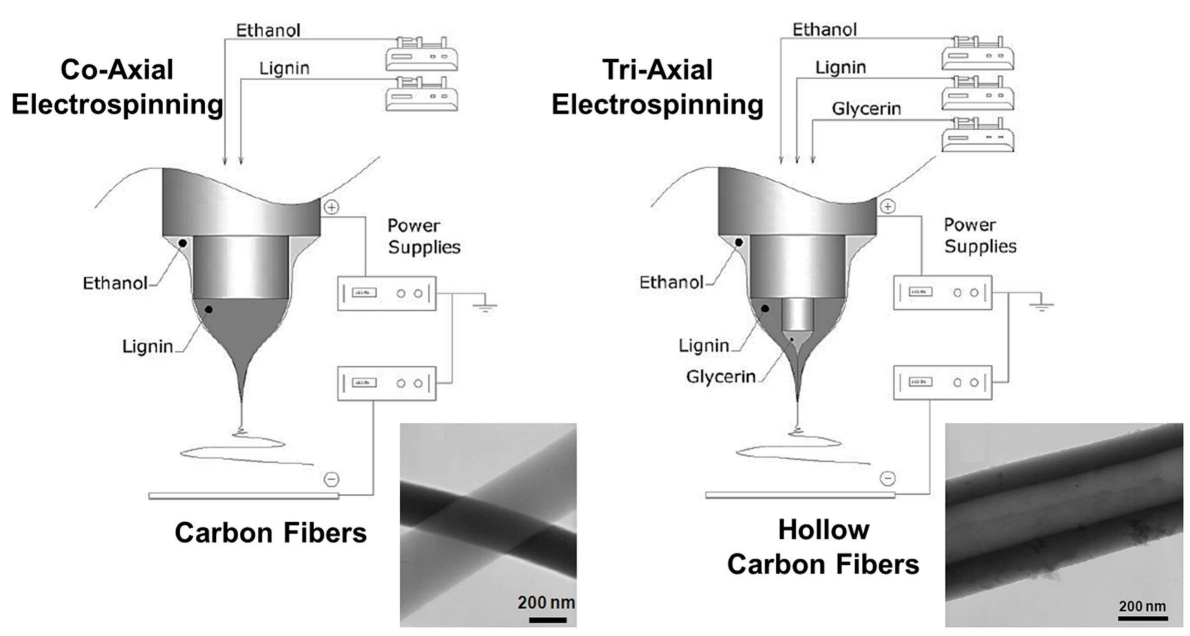

FIGURE 5 | General set-up used in co-axial and tri-axial electrospinning to produce lignin-based CFs and hollow CFs, respectively, adapted from Ruiz-Rosas et al. (2010).

electrospinnability, obtaining a substantial bead formation unless neither a small amount of plasticizing additive is added nor a lignin pre-manipulation is performed (Dallmeyer et al., 2010). A solution of purified SKL in DMF/methanol was electrospun to give fibers with varied morphology and 300-500 $\mathrm{nm}$ average diameters (Hosseinaei and Baker, 2012).

Regarding the use of plasticizing agents, the first attempt was the electrospinning of SKL/PEO blends to obtain electrospun CFs of $\sim 4 \mu \mathrm{m}$ diameter (Montero et al., 2008). Later, Dallmeyer et al. (2010) studied the electrospinning of seven different technical lignins and found a clear transition from electrospray or beaded fibers to uniform fibers upon addition of PEO. More recently, these authors have presented a correlation of the elongational fluid properties to fiber diameter in electrospinning of SKL solutions (Dallmeyer et al., 2014b). Kang and co-workers reported the electrospinning of PAN/alkali-lignin composites (from 100:0 to $20: 80 \mathrm{w} / \mathrm{w}$ ) to prepare submicron fibrous mats of varying morphology. While uniform and thicker fibers (submicron) were produced for lignin contents up to $50 \mathrm{wt} \%$, a remarkably shift to a beaded morphology was observed for higher lignin concentrations. These changes were assigned to a decrease in solution conductivity with the lignin content (Seo et al., 2011; Choi et al., 2013). In another approach, CFs were prepared by electrospinning of alkali-lignin/PVA 9-12 wt\% aqueous mixtures (30/70, 50/50, and 70/30). The average diameters decreased from 300 to $140 \mathrm{~nm}$ with increasing the lignin amount, the finest ever reported lignin-based CFs, what was attributed to a decreasing viscosity and increasing conductivity of the blends (Lai et al., 2014a).

On the other hand, PEO has been also used to enable the incorporation of nanomaterials fillers or chemical activating agents and the control of interconnection, or to avoid the stabilization step on micron-sized electrospun lignin fibers. Some authors studied the electrospinning of $n$-fractionated SKL solutions together with various concentrations of suspended MWCNTs (Lin et al., 2013; Teng et al., 2013). Furthermore, it has been reported that the presence of $10 \mathrm{wt} \%$ PEO enables the efficient electrospinning of aqueous $\mathrm{NaOH}$ or $\mathrm{KOH} /$ Alcali-lignin $\left(\mathrm{AL}_{\mathrm{ls}}\right)$ solutions into fibers ( $\mathrm{Hu}$ and Hsieh, 2013; Hu et al., 2014). Another outstanding method to assist the spinning of advanced fine lignin fibers is the emulsion electrospinning (Lin et al., 2013).

\section{OXIDATIVE THERMOSTABILIZATION}

Because the glass transition temperature $\left(T_{\mathrm{g}}\right)$ of lignins is much lower than those required for their carbonization, lignin fibers have to be subjected to a stabilization pre-treatment to prevent softening. During this treatment, the lignin fiber keeps infusible whenever its $T_{\mathrm{g}}$ is maintained above the process temperature by cross-linking reactions (Braun et al., 2005). Although other stabilization treatments to induce structural cross-linking have been proposed in the literature, like electron beam irradiation, UV radiation, plasma treatment, etc., the simple oxidative thermostabilization in air is by far the most studied and applied method. Despite lignin needs slow heating rates to avoid fusion, the inherent high oxygen content in this polymer enables faster stabilizations than other polymers (PAN, pitches, etc.).

The oxidative stabilization of lignin fibers has been investigated by different authors. Braun et al. (2005) used several characterization techniques to monitor the changes of HKL upon thermostabilization. At lower temperatures, they observed that oxidation reactions form carbonyl and carboxyl structures, while, at higher temperatures, these groups are incorporated into ester and anhydride linkages producing cross-linking within the lignin molecule. Furthermore, from a continuous heating transformation diagram, the optimum heating rate of HKL to keep its $T_{\mathrm{g}}>T$ was predicted to be $0.06^{\circ} \mathrm{C} / \mathrm{min}$. In addition, a recent study reveals that, apart from carbonyl and carboxyl-related structures, stabilization remarkably reduces the proportion of methoxy groups present in hardwood Alcell lignin (Foston et al., 2013). Brodin and co-workers found that the carbon yield of kraft lignin increases as the conditions of its oxidative thermostabilization treatment become harsher (slower heating rates, higher temperatures and 

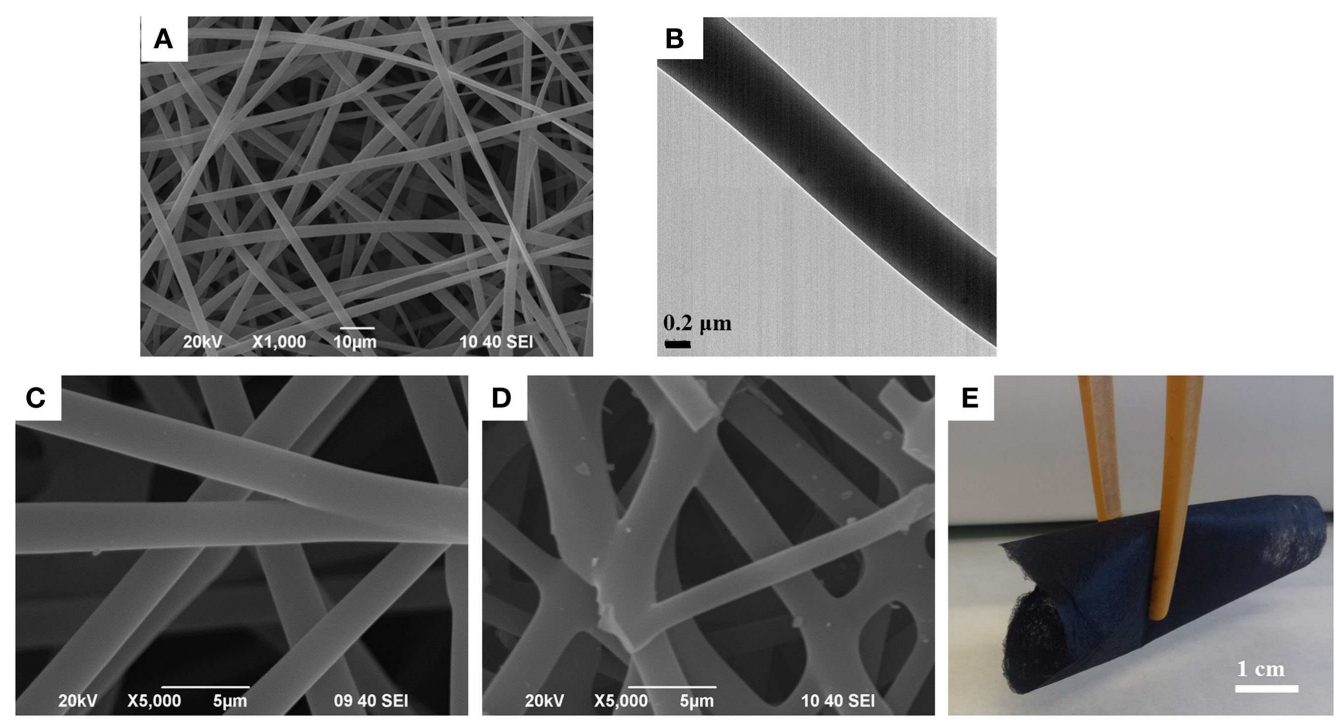

FIGURE 6 | (A) SEM and (B) TEM images of electrospun carbonized lignin fibers; (C,D) SEM images of (C) fragile non-bonded and (D) bonded lignin-based CFs showing the flexibility (E) of the later ones.

longer holding times at this temperature) (Gellerstedt et al., 2010; Brodin et al., 2012). By contrast, Baker and Gallego (2010) found an optimum thermostabilization rate to improve CF yields, below which carbon yield was reduced because the balance of oxidation versus degradation became in favor of the latter, and above which lignin volatilization predominated over oxidation and cross-linking.

In general, thermal pre-treatments under different conditions and/or purification processes with suitable solvents or membranes have been carried out to increase the $T_{\mathrm{g}}$ and $T_{\mathrm{s}}$ of different lignins and their thermostabilization rates (Baker et al., 2009; Hosseinaei and Baker, 2012). In other cases, the co-extrusion with suitable additives (PEO, PET, etc.) enables remarkably faster stabilization processes (Kubo and Kadla, 2005b) or even alleviates the need for the thermal stabilization step (Hu and Hsieh, 2013; Hu et al., 2014).

\section{LIGNIN-BASED CARBON FIBERS FOR STRUCTURAL APPLICATIONS}

As mentioned before, lignin-based CFs were projected to cost much less than any other known method of CF production (Baker and Gallego, 2010). As a result, the optimization of structural properties has been the main objective driving most investigations related to lignin-based CFs. Nevertheless, although the mechanical properties of the lignin-based CFs would fit low grade requirements, with optimized fibers showing tensile strengths up to 1.10 GPa and Young's moduli up to 83-109 GPa (Compere, 2005; Baker and Gallego, 2010), they currently have poor mechanical properties compared with petroleum-derived counterparts and do not meet those required from the automotive industry, i.e., a tensile strength of $1.72 \mathrm{GPa}$, and a modulus of $172 \mathrm{GPa}$ (Warren, 2008; Baker and Gallego, 2010). Hence, much research on the preparation of high-performance lignin-based CFs is currently being done.
In spite of different studies on the carbonization of lignin powder (Rodríguez-Mirasol et al., 1996) or lignin-derived CFs (Baker and Gallego, 2010) revealed the presence of more ordered graphitic structures at elevated temperatures, the early structural investigations carried out by Johnson and Tomizuka (1974) indicated that lignin-based CFs present a low degree of orientation, as well as considerable degree of cross-linking and amount of pores and heterogeneities in their fine structure. Furthermore, the inorganic impurities in lignin precursors act as graphitization catalysts. This provokes density fluctuations and an inhomogeneous melting behavior, thus, preventing any improved tensile strength of the final material.

In this sense, one of the most significant difficulties to produce lignin-derived CFs with enhanced mechanical performance is associated to the heterogeneous nature of lignins (McCarthy and Islam, 2000; Capanema et al., 2004), which also can be strongly modified during the different pulping processes (Lora, 2008). Furthermore, the presence of impurities (ash, etc.) and/or infusible/insoluble components in lignins strongly determine the homogeneity of the CFs (Compere et al., 2004; Suhas et al., 2007). As a consequence, the use of suitable solvents, membranes, and/or thermal treatments, as well as new chemical treatments to purify or modify lignins, respectively, are considered among the most important strategies to enhance the mechanical properties of their derived CFs.

Parallel to the diversity in lignins, there is a lack of knowledge on the influence of the spinning method in the final mechanical properties of lignin-based CFs. Nevertheless, the available literature suggest that the use of plasticizing additives and/or molten lignins via the melt-spinning method may result in more homogeneous lignin fibers and/or facilitate a more homogeneous incorporation of reinforcing fillers. However, the thermal decomposition of the additives and/or cross-linking and degradation of fusible lignins 
during melt-spinning, thermostabilization, and/or carbonization may result in the development of porosity and heterogeneity and/or hinder the mobility and rearrangement of lignin molecules, weakening the obtained CFs. To deal with these problems, a narrow molecular weight distribution (small difference between $T_{\mathrm{g}}$ and $T_{\mathrm{s}}$ ) to ensure uniform increases in molecular weight throughout the material during oxidative thermostabilization, and to provide for a more uniform structure during carbonization, is desirable. Other well-known strategies to strengthen the lignin-based CFs may be their diameter reduction and alignment. This can be readily accomplished through electrospinning, and promising results could arise from aligned or interconnected electrospun lignin fibers obtained from suitable lignins.

Finally, the control of temperature, heating rate, and atmosphere during stabilization and carbonization steps determines not only the time and energy consumption of the overall manufacture process but also the properties of the final carbonized fibers. Thus, during stabilization, the gradual increase in $T_{\mathrm{g}}$ by cross-linking reactions leads to the formation of rigid oxidized segments (Braun et al., 2005) that, although are necessary to avoid fiber swelling and fusion and may increase the carbon yields, could be detrimental to structural carbon order (Hurt and Chen, 2000). However, it has been recently reported that the interconnection in fused CFs enhances the mechanical properties of both the thermostabilized and carbonized materials (Dallmeyer et al., 2014a). An example, see Figures 6C-E. On the other hand, while a high $T_{\mathrm{g}}$ is desired to accelerate the thermostabilization treatment, the achievement of too high temperatures under air atmosphere may cause degradation of lignins and, therefore, more defective or heterogeneous CFs. This compromise relationship among thermostabilization rate, thermal degradation, and cross-linking and mechanical properties demands for a precise control of the process that remarkably hinders the manufacture of lignin-based CFs.

Up to now, the best mechanical properties were obtained by Compere (2005), which evaluated the mechanical properties of soda HAL-PET fibers carbonized at $1200^{\circ} \mathrm{C}$, reaching tensile strengths up to $1.03 \mathrm{GPa}$ and Young's modulus up to $109 \mathrm{GPa}$, and by Baker and Gallego (2010), which reported CFs, from purified Alcell lignin, with an average tensile strength of $1.07 \mathrm{GPa}$ and moduli of $82.7 \mathrm{GPa}$, as well as $55 \%$ of carbon yield.

\section{LIGNIN-BASED CARBON FIBERS FOR FUNCTIONAL APPLICATIONS}

As aforementioned, CFs can be used for functional applications (adsorption, catalysis, energy storage and conversion, etc.) in which other properties, such as a high surface area and/or a suitable porosity, surface chemistry, electrical conductivity, and oxidation resistance are considered more important than the mechanical ones.

Different methods have been proposed in the literature to obtain AC fibers (ACFs), which can be used in these functional applications. However, to date, the advantageous use of lignin as precursor of lower cost ACFs has been much lesser studied. The different routes to fabricate porous CFs from lignin could be divided into chemical, physical, or inherently driven activation. In his patent, Otani et al. (1969) claimed the production of highly activated CFs, through wet- dry-, and melt-spinning, by the introduction of various chemical agents in the molten lignin (sulfur,
$\left.\mathrm{ZnCl}_{2}\right)$ or in the solvents in which lignin is dissolved $(\mathrm{NaOH}, \mathrm{KOH}$, $\mathrm{H}_{2} \mathrm{SO}_{4}$ ) and/or by treatment with an activating gas (air, oxygen, stream, etc.) just after carbonization. The claimed ACFs of 15$30 \mu \mathrm{m}$ diameter showed MB adsorptive powers of $8-25 \mathrm{~cm}^{3}$ as well as chemical and heat resistances, electrical conductivity, and/or textile flexibility (Otani et al., 1969). Recently, submicron ACFs prepared by electrospinning of (ALls)/PEO ( $9 / 1 \mathrm{w} / \mathrm{w})$ together with $\mathrm{NaOH}$ or $\mathrm{KOH}$ showed very high $A_{\mathrm{BET}}$ (up to $1400 \mathrm{~m}^{2} / \mathrm{g}$ ) with over $85 \%$ attributed to micropores (Hu and Hsieh, 2013). As for physical activation, Uraki and co-workers investigated the preparation of ACFs from acetic acid hardwood (HAL) and softwood (SAL) lignins by steam activation. The HAL-based ACF, activated for $40 \mathrm{~min}$ at $900^{\circ} \mathrm{C}$, had excellent properties, such as more rapid adsorption rate and comparable or superior iodine and $\mathrm{MB}$ adsorption capacities to those commercially available AC powders (Uraki et al., 1997). The authors also reported the use of SAL, free from the high-molecular-mass fraction, to yield ACF with a faster thermostabilization step and larger $A_{\mathrm{BET}}\left(1930 \mathrm{~m}^{2} / \mathrm{g}\right)$ and pore volume $\left(0.523 \mathrm{~cm}^{3} / \mathrm{g}\right)$ than that from HAL. It was found that SAL-ACF had adsorption properties comparable to those of high-performance commercial ACF and a tensile strength equal to that of a pitch-derived ACF (Kubo et al., 1998). On the other hand, several lignin-based ACFs with controllable pore size properties were prepared from LPF resins with varied lignin contents, 8-20\% (Qing et al., 2011). Lin et al. (2012) reported the steam activation of CFs, from thermally fusible softwood (cedar) PEGlignin, at $900^{\circ} \mathrm{C}$ for 30,60 , and $90 \mathrm{~min}$ to give rise to $A_{\mathrm{BET}}$ of 2038,2442 , and $3060 \mathrm{~m}^{2} / \mathrm{g}$, respectively (the highest ever reported from any lignin precursor) indicating the promising use of this precursor for the manufacture of ACFs.

Based on their specific composition, the carbonization of different pure or composite lignin fibers can result in highly porous fibrous materials (inherently driven activation). Kubo et al. (2007) studied the porosity of $\mathrm{HKL} / \mathrm{PP}$-derived CFs and found that, during the thermostabilization process, pores are created by oxidative degradation of PP, whereas upon carbonization, the residual $\mathrm{PP}$ is subsequently pyrolyzed to effectively create porosity (up to $\sim 500 \mathrm{~m}^{2} / \mathrm{g}$ ) in the resulting CFs. Similarly, the carbonization of electrospun lignin/PVA (70/30) fibers resulted in $A_{\mathrm{BET}}$ of $\sim 580 \mathrm{~m}^{2} / \mathrm{g}$ (Lai et al., 2014a).

More interestingly, the carbonization of electrospun Alcell lignin gave rise to microporous $\mathrm{CF}$ with high $A_{\mathrm{BET}}$ and pore volumes of up to $1200 \mathrm{~m}^{2} / \mathrm{g}$ and $0.520 \mathrm{~cm}^{3} / \mathrm{g}$, respectively. This remarkable porosity development was assigned to the high oxygen contents in the stabilized precursors $(\sim 33 \mathrm{wt} \%)$, which could act as inherent activating agent during the subsequent carbonization process. In spite of their high porosity and small diameter, and even containing Pt (a well-known catalyst for carbon oxidation), these CFs showed a remarkably high oxidation resistance (those carbonized at $900^{\circ} \mathrm{C}$ start to oxidize above $500^{\circ} \mathrm{C}$ ) (Figure 7). The presence of Pt only slightly reduces the oxidation resistance. The high oxidation resistance was assigned to a certain degree of structural order and to the lack of surface defects achieved upon carbonization. Furthermore, the same authors carried out a study of the thermal oxidation mechanism of the fibers. At lower carbon burn-offs, the reaction proceeds mainly over the external fiber surface, but it also affects the inner surface at near complete oxidation 

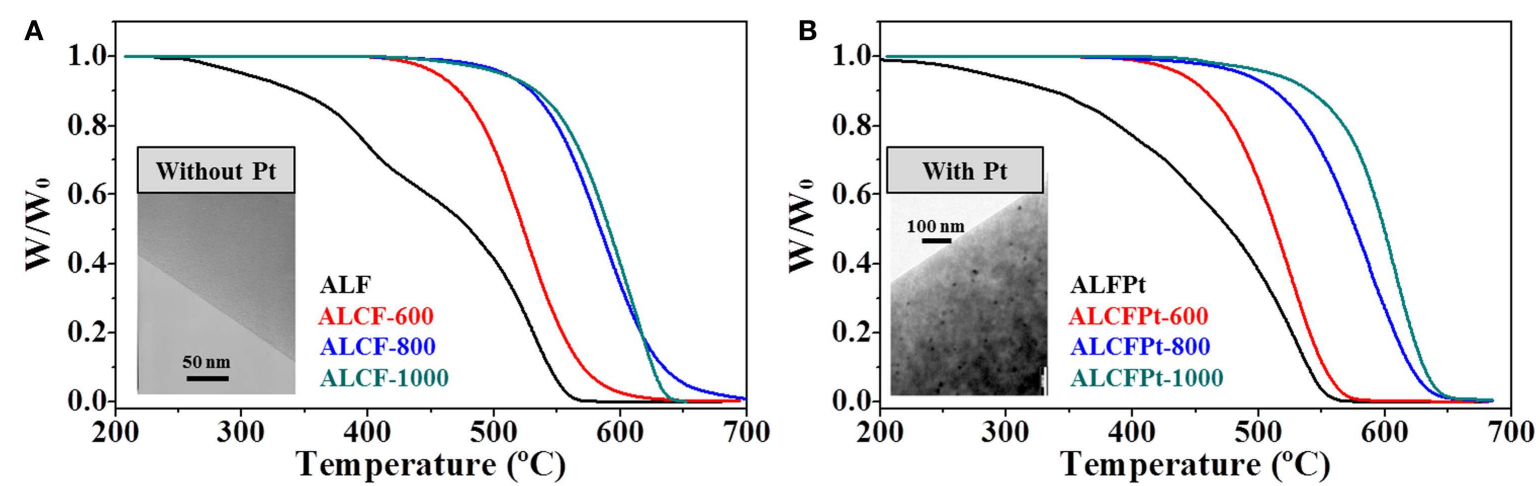

FIGURE 7 | Oxidation resistance profiles in air atmosphere of non-stabilized and carbonized lignin-derived CFs (A) without platinum and (B) with platinum adapted from Ruiz-Rosas et al. (2010).

( $90 \%$ BO). Because of a wider microporosity induced by $\mathrm{Pt}$, the presence of the metal results in a more homogeneous oxidation of the fibers (Ruiz-Rosas et al., 2010).

\section{Carbon fibers as electrodes for electrochemical devices}

The utilization of more continuous and/or self-standing carbon materials in the shape of various fibrous structures (fibers, tubes, fabrics, meshes, webs, etc.) as electrodes in different electrochemical devices for energy storage and conversion is receiving a growing interest in recent years. Major advantages arise from their much lower inter-particle resistance and the lack of need for expensive additives (binders and conductivity promoters) that make complex the manufacture process. Dallmeyer et al. (2014a) found that the conductivity of interconnected Kraft lignin-based sub- $\mu \mathrm{m}$ diameter CFs were much higher than that of the corresponding non-bonded materials, and that the obtained conductivities (0.6$19.6 \mathrm{~S} / \mathrm{cm}$ ), were comparable to those of other electrospun CFs based on phenolic resin or PAN. In this sense, the use of ligninderived fibrous carbon materials for applications in energy storage systems like lithium-ion batteries (LIBs), supercapacitors (electrochemical capacitor), or fuel cells has been recently reported.

In the case of LIBs, Wang et al. reported that fusion and $\mathrm{N}$ doping (up to $12.6 \mathrm{wt} \%$ ) enhance the electrical conductivity (10.53 and $12.24 \mathrm{~S} / \mathrm{cm}$, respectively) and LIB specific capacity (445 and $576 \mathrm{mAh} / \mathrm{g}$, respectively, at $30 \mathrm{~mA} / \mathrm{g}$ ) of freestanding CFs prepared by electrospinning of organosolv-lignin/PEO ( $\geq 10 \mathrm{wt} \%$ ) blends. In addition, $\mathrm{N}$-doped fused CFs still maintained a good capacity of $\sim 200 \mathrm{mAh} / \mathrm{g}$ even at a high current rate of $2 \mathrm{~A} / \mathrm{g}$ (Wang et al., 2013). On the other hand, Tenhaeff et al. have recently used fused fibrous carbon materials, from melt-spinning of Alcell lignin, exhibiting specific charge capacities comparable to conventional graphitic anodes in LIBs $\left(350 \mathrm{mAh} / \mathrm{g}\right.$ when carbonized at $\left.1000^{\circ} \mathrm{C}\right)$. Carbonization at higher temperatures $\left(1500-2000^{\circ} \mathrm{C}\right)$ resulted in greater graphitization and lower specific charge capacities, but significant improvements in the first cycle efficiencies (Tenhaeff et al., 2014).

Good performance has been also demonstrated for supercapacitors and fuel cells. ACFs from $\mathrm{KOH}$ activation of electrospun (ALls)/PEO $(9 / 1 \mathrm{w} / \mathrm{w})$ blends showed very high specific capacitance of $344 \mathrm{~F} / \mathrm{g}$ at low electrode mass and scan rate $\left(1.8 \mathrm{mg} / \mathrm{cm}^{2}\right.$ and $10 \mathrm{mV} / \mathrm{s}$, respectively) in $6 \mathrm{M} \mathrm{KOH}$ aqueous electrolyte, which was maintained at $196 \mathrm{~F} / \mathrm{g}$ for $10 \mathrm{mg} / \mathrm{cm}^{2}$ and $50 \mathrm{mV} / \mathrm{s}$, giving rise to a high average energy density of $8.1 \mathrm{Wh} / \mathrm{kg}$. Furthermore, over $96 \%$ capacitance retention was achieved after 5000 charge/discharge cycles (Hu et al., 2014). On the other hand, mechanically flexible ACFs from electrospun alkali-lignin/PVA 70/30 aqueous mixtures were found to exhibit capacitances (twoelectrode cell) of 64 and $50 \mathrm{~F} / \mathrm{g}$ at current densities of 400 and $2000 \mathrm{~mA} / \mathrm{g}$, respectively, in $6 \mathrm{M} \mathrm{KOH}$ aqueous electrolyte. Moreover, the electrode capacitance merely reduced by $\sim 10 \%$ after 6000 cycles (Lai et al., 2014b). In another work, Ag nanoparticles supported on electrospun lignin-based CFs (AgNPs/CFs electrocatalysts) have exhibited high activity toward oxygen reduction reaction (ORR) and a close-to-theoretical four-electron pathway in $0.1 \mathrm{M} \mathrm{KOH}$ aqueous solution. In particular, the mass activity of $15 \mathrm{wt} \%$ AgNPs/CFs system was the highest (119 mA/mg), exceeding even that of a commercial $\mathrm{Pt} / \mathrm{C}$ catalyst $(98 \mathrm{~mA} / \mathrm{mg})$, thus, suggesting lignin-derived CFs as promising low-cost supports for highly efficient ORR electrocatalysts in alkaline fuel cells.

\section{TEMPLATED CARBONS}

In recent years, an intense research on the preparation of materials with controlled pore systems at different length scales has been taking place, since an adequate control of the pore size plays a key role in carbon material properties and performance (Ruiz-Rosas et al., 2014; Saha et al., 2014a). In this context, nanostructured carbons with hierarchical pore arrangement, known as hierarchical porous carbons (HPCs), have shown outstanding behavior in different applications because of the different ranges of interconnected pores.

The preparation of both hierarchical mesopore-micropore carbons and micropore materials with a highly ordered pore structure usually involves the use of the nanocasting technique, which implies a reverse replication of the pore system from a porous material as sacrifice template. Nanostructured carbons with hierarchical pore arrangement (ordered micro- and mesopore network) can be prepared by liquid phase impregnation (LPI) of the pores of a hard template. On the other hand, microporous carbons with a three-dimensional connected and ordered pore structure can be prepared by chemical vapor deposition (CVD) of a light 
hydrocarbon over a zeolitic material, which is later removed by acid-etching. The preparation of carbon materials by CVD goes out of the goal of this review, since it is only focused on the use of lignin as carbonaceous precursor.

In this sense, Fierro et al. (2013) synthesized microporousmesoporous carbons via colloidal silica templating by using microwave pretreated Kraft lignin in sodium bicarbonate solution, as a carbon precursor. The authors obtained tunable mesopores after dissolving colloidal silica used as a hard template, whereas the microporosity was created by a post-synthesis $\mathrm{CO}_{2}$ activation method. The resulting activated lignin-based carbons possessed high $A_{\mathrm{BET}}$ (up to $2000 \mathrm{~m}^{2} / \mathrm{g}$ ) and microporosity and mesoporosity easily tunable by adjusting activation conditions and optimizing

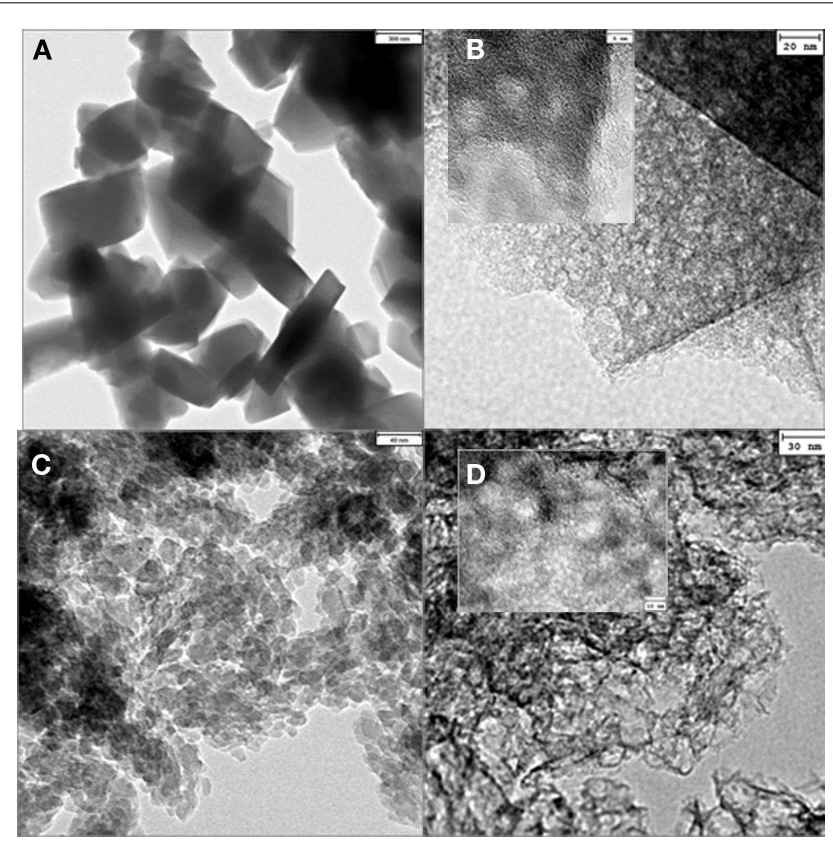

FIGURE 8 |TEM micrographs of the Y zeolite, bar length: $300 \mathrm{~nm}(A)$ and L-Y-700 carbon, bar length: $20 \mathrm{~nm}$ (inset: $5 \mathrm{~nm}$ ) (B); $\beta$ zeolite, bar length: $40 \mathrm{~nm}(C)$ and L- $\beta-900$ carbon, bar length: $30 \mathrm{~nm}$ (inset $10 \mathrm{~nm}$ ) (D). the amount and particle size of the colloidal silica used. The total pore volumes of ACs obtained by using 20 and $13 \mathrm{~nm}$ silica colloids as a hard template exceeded 1 and $2 \mathrm{~cm}^{3} / \mathrm{g}$, respectively. More recently, Saha et al. (2014a,b) have also reported the preparation of mesoporous carbons with an ordered porous structure using Alcell lignin as a natural carbon precursor, but in their case, a surfactant is used as the sacrifice template. In this new templating technique, named surfactant templating synthesis, the mesoporous carbon is synthesized by cross-linking a suitable organic resin in the presence of some sacrificial surfactants, followed by pyrolysis leading to removal of the surfactant and subsequent carbonization of the matrix. The obtained carbon had a BET surface area of $200 \mathrm{~m}^{2} / \mathrm{g}$ and pore volume of $0.2 \mathrm{~cm}^{3} / \mathrm{g}$. The novelty of these works arises from the use of this mesoporous carbon to control the release of different model drugs, such as captopril, furosemide, ranitidine hydrochloride, and antipyrine, as a relatively newer type of drug-delivery medium.

On the other hand, Valero-Romero et al. (2014) reported the preparation of carbon materials with hierarchical pore structures by liquid-phase impregnation technique with Alcell lignin solutions as the carbon precursor and different zeolites as inorganic templates. The impregnation ratio of $1: 1$ ( $1 \mathrm{~g}$ of lignin and $1 \mathrm{~g}$ of zeolite $\mathrm{Y}$ and $\beta$, respectively) was selected as the optimum combination for the development of structures with different levels of micro-and mesoporosity development. The infiltrated samples were further dried and carbonized under continuous inert flow. The carbon/zeolite composites prepared through this impregnation method were soaked in $\mathrm{NaOH}$ solution to remove the zeolite template. As an example, the TEM images of the parent zeolites and their respective TCs, shown in Figure 8, provide evidence to support the different origins of mesoporosity. Images from Y- and $\beta$-based TCs, Figures $\mathbf{8 B}, \mathbf{D}$, proved that these materials present similar morphologies to those of the hard templates, indicating the adequate replication of the zeolites. Inset in Figures $\mathbf{8 B}, \mathbf{D}$ provides evidence of a population of mesopores with sizes around 3 and $10 \mathrm{~nm}$, for Y- and $\beta$-based TCs, respectively. In addition to the structural properties, a very interesting feature observed was the presence of oxygen and nitrogen functional groups. The contribution of nitrogen on the TCs was reported to be due to the ammonium cation in zeolite templates, which participated in
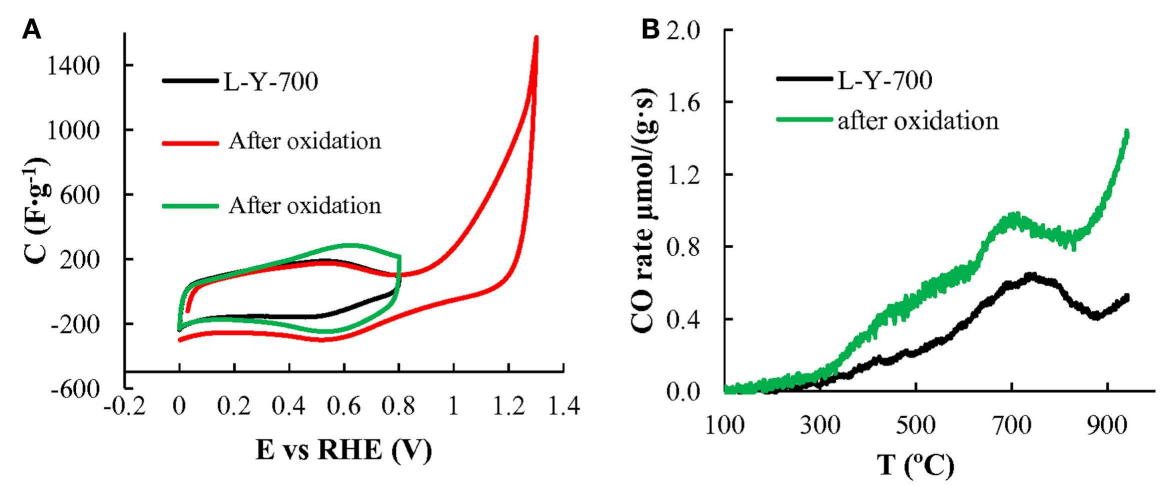

FIGURE 9 | (A) Cyclic voltammograms of L-Y-700 before oxidation and after oxidation between 0 and $1.2 \mathrm{~V}$ and between 0 and $0.8 \mathrm{~V}$ (B) CO TPD evolution profiles obtained from L-Y-700 before and after the electrochemical oxidation treatment, adapted from Ruiz-Rosas et al. (2014). 
the reactions during the carbonization step at high temperatures to form carbon surface- $\mathrm{N}$ species, such as, pyridine-like species and highly coordinated quaternary nitrogen atoms (pyrrolic or amine moieties). On the other hand, the oxygen presented in the TCs, consisted mainly of carbonyl, phenolic, and anhydride groups, which might have been derived from the dehydroxilation of zeolites during the carbonization.

Figure 9 shows the voltammograms obtained for L-Y-700, whereas Figure 9B shows the CO-TPD profiled of L-Y-700 before and after the electrochemical oxidation treatment. The results showed that these materials can be easily electro-oxidized in sulfuric acid electrolyte under positive polarization, producing a large amount of CO-evolving surface oxygen groups that enhance the pseudocapacitance by $30 \%$ without compromising the rate performance. This seems to be a consequence of the high concentration of active sites of the carbon fraction generated from the infiltration in the zeolite. These lignin-based templated carbons showed a specific capacitance as high as $250 \mathrm{~F} / \mathrm{g}$, at $50 \mathrm{~mA} / \mathrm{g}$, with a capacitance retention of $50 \%$ and volumetric capacitance of $75 \mathrm{~F} / \mathrm{cm}^{3}$ at currents higher than $20 \mathrm{~A} / \mathrm{g}$ thanks to their interconnected porous texture (Ruiz-Rosas et al., 2014).

\section{ACKNOWLEDGEMENTS}

This work was supported by the Spanish Ministry of Economy and Competitiveness under CTQ2012-36408 project and by Junta de Andalucia (P09-FQM-5156 and P10-FQM-6778).

\section{REFERENCES}

Adler, E. (1977). Lignin chemistry - past, present and future. Wood. Sci. Technol. 11, 169-218. doi:10.1007/BF00365615

Babel, K., and Jurewicz, K. (2008). KOH activated lignin based nanostructured carbon exhibiting high hydrogen electrosorption. Carbon N. Y. 46, 1948-1956. doi:10.1016/j.carbon.2008.08.005

Baker, D. A., Baker, F. S., and Gallego, N. C. (2009). "Thermal engineering of lignin for low-cost production of carbon fiber," in Book of Abstracts of The Fiber Society 2009 Fall Conference (Georgia: The Fiber Society), 54-55.

Baker, D. A., Gallego, N. C., and Baker, F. S. (2008a). "Carbon fiber production from a Kraft hardwood lignin," in Book of Abstracts of The Fiber Society 2008 Fall Conference (Québec: The Fiber Society), 106-107.

Baker, F. S., Gallego, N. C., and Baker, D. A. (2008b). "Low cost carbon fiber from renewable resources," in DOE FY 2008 Progress Report for Lightweighting Materials, Part 7.A (Washington, DC: U.S. Department of Energy), 1-18.

Baker, D. A., Harper, D. P., and Rials, T. G. (2012). "Carbon fiber from extracted commercial softwood lignin," in Book of Abstracts of The Fiber Society 2012 Fall Conference (Boston: The Fiber Society), 17-18.

Baker, F. S., and Gallego, N. C. (2010). "Low cost carbon fiber from renewable resources," in DOE FY 2010 Progress Report for Lightweighting Materials, Part 3.C (Washington, DC: U.S. Department of Energy), 32-34.

Baklanova, O. N., Plaksin, G. V., Drozdov, V. A., Duplyakin, V. K., Chesnokov, N. V., and Kuznetsov, B. N. (2003). Preparation of microporous sorbents from cedar nutshells and hydrolytic lignin. Carbon N. Y. 41, 1793-1800. doi:10.1016/S0008-6223(03)00149-0

Bedia, J., Rodriguez-Mirasol, J., and Cordero, T. (2007). Water vapour adsorption on lignin-based activated carbons. J. Chem. Technol. Biotechnol. 82, 548-557. doi:10.1002/jctb.1698

Bedia, J., Rosas, J. M., Márquez, J., Rodríguez-Mirasol, J., and Cordero, T. (2009). Preparation and characterization of carbon based acid catalysts for the dehydration of 2-propanol. Carbon N. Y. 47, 286-294. doi:10.1002/jctb.1698

Bedia, J., Rosas, J. M., Rodríguez-Mirasol, J., and Cordero, T. (2010). Pd supported on mesoporous activated carbons with high oxidation resistance as catalysts for toluene oxidation. Appl. Catal. B Environ. 94, 8-18. doi:10.1016/j.apcatb.2009. 10.015
Bissett, P. J., and Herriott, C. W. (2012). Lignin/Polyacrylonitrile-Containing Dopes, Fibers and Production Methods. US 20120003471 and WO 2012003070.

Braun, J. L., Holtman, K. M., and Kadla, J. F. (2005). Lignin-based carbon fibers: oxidative thermostabilization of Kraft lignin. Carbon N. Y. 43, 385-394. doi:10.1016/j.carbon.2004.09.027

Brodin, I., Ernstsson, M., Gellerstedt, G., and Sjöholm, E. (2012). Oxidative stabilisation of Kraft lignin for carbon fibre production. Holzforschung 66, 141-147. doi:10.1515/HF.2011.133

Capanema, E. A., Balakshin, M. Y., and Kadla, J. F. (2004). A comprehensive approach for quantitative lignin characterization by NMR spectroscopy. J. Agric. Food Chem. 52, 1850-1860. doi:10.1021/jf035282b

Carrott, P. J. M., Suhas, Ribeiro-Carrott, M. M. L., Guerrero, C. R., and Delgado, L. A. (2008). Reactivity and porosity development during pyrolysis and physical activation in $\mathrm{CO} 2$ or steam of Kraft and hydrolytic lignins. J. Anal. Appl. Pyrolysis 82, 264-271. doi:10.1016/j.jaap.2008.04.004

Choi, D. I., Lee, J.-N., Song, J., Kang, P.-H., Park, J.-K., and Lee, Y. M. (2013). Fabrication of polyacrylonitrile/lignin-based carbon nanofibers for high-power lithium ion battery anodes. J. Solid State Electrochem. 17, 2471-2475. doi:10. 1007/s10008-013-2112-5

Compere, A. L. (2005). Evaluation of Lignin from Alkaline-Pulped Hardwood Black Liquor (Reports of the Oak Ridge National Laboratory).

Compere, A. L., Griffith, W. L., Leitten, C. F., and Petrovan, S. (2004). "Improving the fundamental properties of lignin-based carbon fiber for transportation applications," in Proceedings of the 36th International SAMPE Technical Conference (Covina: Society for the Advancement of Material and Process Engineering), 2246-2254.

Cotoruelo, L. M., Marqués, M. D., Díaz, F. J., Rodríguez-Mirasol, J., Cordero, T., and Rodríguez, J. J. (2007a). Activated carbons from lignin: their application in liquid phase adsorption. Sep. Sci. Technol. 42, 3363-3389. doi:10.1080/ 01496390701626800

Cotoruelo, L. M., Marqués, M. D., Rodríguez-Mirasol, J., Cordero, T., and Rodríguez, J. J. (2007b). Adsorption of aromatic compounds on activated carbons from lignin: equilibrium and thermodynamic study. Ind. Eng. Chem. Res. 46, 4982-4990. doi:10.1021/ie061415h

Cotoruelo, L. M., Marqués, M. D., Díaz, F. J., Rodríguez-Mirasol, J., Rodríguez, J. J., and Cordero, T. (2009). Lignin-based activated carbons for adsorption of sodium dodecylbenzene sulfonate: equilibrium and kinetic studies. J. Colloid Interface Sci. 332, 39-45. doi:10.1016/j.jcis.2008.12.031

Cotoruelo, L. M., Marqués, M. D., Díaz, F. J., Rodríguez-Mirasol, J., Rodríguez, J. J., and Cordero, T. (2010). Equilibrium and kinetic study of congo red adsorption onto lignin-based activated carbons. Transp. Porous Med. 83, 573-590. doi:10.1007/s11242-009-9460-8

Cotoruelo, L. M., Marqués, M. D., Díaz, F. J., Rodríguez-Mirasol, J., Rodríguez, J. J., and Cordero, T. (2012a). Adsorbent ability of lignin-based activated carbons for the removal of p-nitrophenol from aqueous solutions. Chem. Eng. J. 184, 176-183. doi:10.1016/j.cej.2012.01.026

Cotoruelo, L. M., Marqués, M. D., Díaz, F. J., Rodríguez-Mirasol, J., Rodríguez, J. J., and Cordero, T. (2012b). Lignin-based activated carbons as adsorbents for crystal violet removal from aqueous solutions. Environ. Progr. Sust. Energy 31, 386-396. doi:10.1002/ep.10560

Cotoruelo, L. M., Marqués, M. D., Rodríguez-Mirasol, J., Rodríguez, J. J., and Cordero, T. (2011a). Cationic dyes removal by multilayer adsorption on activated carbons from lignin. J. Porous Mater. 18, 693-702. doi:10.1007/s10934010-9428-7

Cotoruelo, L. M., Marqués, M. D., Leiva, A., Rodríguez-Mirasol, J., and Cordero, T. (2011b). Adsorption of oxygen-containing aromatics used in petrochemical, pharmaceutical and food industries by means of lignin based active carbons. Adsorption 17, 539-550. doi:10.1007/s10450-010-9319-x

Dallmeyer, I., Ko, F., and Kadla, J. F. (2010). Electrospinning of technical lignins for the production of fibrous networks. J. Wood Chem. Technol. 30, 315-329. doi:10.1080/02773813.2010.527782

Dallmeyer, I., Lin, L. T., Li, Y., Ko, F., and Kadla, J. F. (2014a). Preparation and characterization of interconnected, Kraft lignin-based carbon fibrous materials by electrospinning. Macromol Mater. Eng. 299, 540-551. doi:10.1002/mame. 201300148

Dallmeyer, I., Ko, F., and Kadla, J. F. (2014b). Correlation of elongational fluid properties to fiber diameter in electrospinning of softwood Kraft lignin solutions. Ind. Eng. Chem. Res. 53, 2697-2705. doi:10.1021/ie403724y 
Eckert, R. C., and Abdullah, Z. (2008). Carbon Fibers from Kraft Softwood Lignin. US 20080317661.

Fierro, C. M., Gorka, J., Zazo, J. A., Rodriguez, J. J., Ludwinowicz, J., and Jaroniec, M. (2013). Colloidal templating synthesis and adsorption characteristics of microporous-mesoporous carbons from Kraft lignin. Carbon N. Y. 62, 233-239. doi:10.1021/ef060097w

Fierro, V., Torne-Fernandez, V., and Celzard, A. (2006). Kraft lignin as a precursor for microporous activated carbons prepared by impregnation with orthophosphoric acid: synthesis and textural characterisation. Microporous Mesoporous Mater. 92, 243-250. doi:10.1016/j.micromeso.2006.01.013

Fierro, V., Torne-Fernandez, V., and Celzard, A. (2007a). Highly microporous carbons prepared by activation of Kraft lignin with KOH. Studies Surf. Sci. Catal. $160,607-614$.

Fierro, V., Torne-Fernandez, V., and Celzard, A. (2007b). Methodical study of the chemical activation of Kraft lignin with $\mathrm{KOH}$ and $\mathrm{NaOH}$. Microporous Mesoporous Mater. 101, 419-431. doi:10.1016/j.micromeso.2006.12.004

Fierro, V., Torne-Fernandez, V., Celzard, A., and Montane, D. (2007c). Influence of the demineralisation on the chemical activation of Kraft lignin with orthophosphoric acid. J. Hazard. Mater. 149, 126-133. doi:10.1016/j.jhazmat.2007.03.056

Foston, M., Nunnery, G. A., Meng, X., Sun, Q., Baker, F. S., and Ragauskas, A. (2013). NMR a critical tool to study the production of carbon fiber from lignin. Carbon N. Y. 52, 65-73. doi:10.1016/j.carbon.2012.09.006

Frank, E., Steudle, L. M., Ingildeev, D., Spörl, J. M., and Buchmeiser, M. R. (2014). Carbon fibers: precursor systems, processing, structure, and properties. Angew. Chem. Int. Ed. Engl. 53, 5262-5298. doi:10.1002/anie.201306129

Fu, K., Yue, Q., Gao, B., Sun, Y., and Zhu, L. (2013). Preparation, characterization and application of lignin-based activated carbon from black liquor lignin by steam activation. Chem. Eng. J. 228, 1074-1082. doi:10.1016/j.cej.2013.05.028

Fukuoka, Y. (1969). Method for producing carbonized lignin fiber. Jpn. Chem. Q. 5, 63-66.

Gao, Y., Yue, Q., Gao, B., Sun, Y., Wang, W., Li, Q., et al. (2013). Preparation of high surface area-activated carbon from lignin of papermaking black liquor by $\mathrm{KOH}$ activation for $\mathrm{Ni}(\mathrm{II})$ adsorption. Chem. Eng. J. 217, 345-353. doi:10.1016/j.cej.2012.09.038

Gellerstedt, G., Sjoeholm, E., and Brodin, I. (2010). The wood-based biorefinery: a source of carbon fiber? Open Agric. J. 3, 119-124. doi:10.2174/ 1874331501004010119

Gonzalez-Serrano, E., Cordero, T., Rodriguez-Mirasol, J., Cotoruelo, L. M., and Rodriguez, J. J. (2004). Removal of water pollutants with activated carbons prepared from H3PO4 activation of lignin from Kraft black liquors. Water Res. 38, 3043-3050. doi:10.1016/j.watres.2004.04.048

Gonzalez-Serrano, E., Cordero, T., Rodriguez-Mirasol, J., and Rodrıguez, J. J. (1997). Development of Porosity upon Chemical Activation of Kraft Lignin with $\mathrm{ZnCl}_{2}$. Ind. Eng. Chem. Res. 36, 4832-4838. doi:10.1021/ie970261q

Gould, A. M. (1974). Manufacture of Carbon Fibre. GB 1358164 A.

Guillen, E., Rico, R., Lopez-Romero, J. M., Bedia, J., Rosas, J. M., Rodriguez-Mirasol, J., et al. (2009). Pd-activated carbon catalysts for hydrogenation and Suzuki reactions. Appl. Catal. A Gen. 368, 113-120. doi:10.1016/j.apcata.2009.08.016

Guo, Y., and Rockstraw, D. A. (2006). Physical and chemical properties of carbons synthesized from xylan, cellulose, and Kraft lignin by H3PO4 activation. Carbon N. Y. 44, 1464-1475. doi:10.1016/j.carbon.2005.12.002

Hayashi, J., Kazehaya, A., Muroyama, K., and Watkinson, A. O. (2000). Preparation of activated carbon from lignin by chemical activation. Carbon N. Y. 38, 1873-1878. doi:10.1016/S0008-6223(00)00027-0

Hayashi, J., Muroyama, K., Gomes, V. G., and Watkinson, A. O. (2002). Fractal dimensions of activated carbons prepared from lignin by chemical activation. Carbon N. Y. 40, 617-636. doi:10.1016/S0008-6223(02)00017-9

Hosseinaei, O., and Baker, D. A. (2012). "Electrospun carbon nanofibers from Kraft lignin," in Book of Abstracts of The Fiber Society 2012 Fall Conference (Boston: The Fiber Society), 19-20.

Hu, S., and Hsieh, Y.-L. (2013). Ultrafine microporous and mesoporous activated carbon fibers from alkali lignin. J. Mater. Chem. A 1, 11279-11288. doi:10.1039/C3TA12538F

Hu, S., Zhang, S., Pan, N., and Hsieh, Y.-L. (2014). High energy density supercapacitors from lignin derived submicron activated carbon fibers in aqueous electrolytes. J. Power Sources 270, 106-112. doi:10.1016/j.jpowsour. 2014.07.063

Hurt, R. H., and Chen, Z.-Y. (2000). Liquid crystals and carbon materials. Phys. Today 53, 39-44. doi:10.1063/1.883020
Ioannidou, O., and Zabaniotou, A. (2007). Agricultural residues as precursors for activated carbon production. Sustain. Energy Rev. 11, 1966-2005. doi:10.1016/j. rser.2006.03.013

Johnson, D. J., and Tomizuka, I. (1974). “The fine structure of lignin- and pitchbased carbon fibers," in Carbon Fibres: Their Place in Modern Technology (Plastics and Polymers Conference Supplement No. 6), ed. J. Mountifield (London: Plastics Institute), 20-24.

Kadla, J. F., Kubo, S., Venditti, R. A., Gilbert, R. D., Compere, A. L., and Griffith, W. (2002a). Lignin-based carbon fibers for composite fiber applications. Carbon 40, 2913-2920. doi:10.1016/S0008-6223(02)00248-8

Kadla, J. F., Kubo, S., Venditti, R. A., and Gilbert, R. D. (2002b). Novel hollow core fibers prepared from lignin polypropylene blends. J. Appl. Polym. Sci. 85, 1353-1355. doi:10.1002/app.10640

Khezami, L., Chetouani, A., Taouk, B., and Capart, R. (2005). Production and characterisation of activated carbon from wood components in powder: cellulose, lignin, xylan. Powder Technol. 157, 48-56. doi:10.1016/j.powtec.2005.05.009

Kijima, M., Hirukawa, T., Hanawa, F., and Hata, T. (2011). Thermal conversion of alkaline lignin and its structured derivatives to porous carbonized materials. Biores. Technol. 102, 6279-6285. doi:10.1016/j.biortech.2011.03.023

Kubo, S., and Kadla, J. F. (2003). The formation of strong intermolecular interactions in immiscible blends of poly(vinyl alcohol) (PVA) and lignin. Biomacromolecules 4, 561-567. doi:10.1021/bm025727p

Kubo, S., and Kadla, J. F. (2004). Poly(ethylene oxide)/organosolv lignin blends: relationship between thermal properties, chemical structure, and blend behavior. Macromolecules 37, 6904-6911. doi:10.1021/ma0490552

Kubo, S., and Kadla, J. F. (2005a). Kraft lignin/poly(ethylene oxide) blends: effect of lignin structure on miscibility and hydrogen bonding. J. Appl. Polym. Sci. 98, 1437-1444. doi:10.1002/app.22245

Kubo, S., and Kadla, J. F. (2005b). Lignin-based carbon fibers: effect of synthetic polymer blending on fiber properties. J. Polym. Environ. 13, 97-105. doi:10.1007/s10924-005-2941-0

Kubo, S., Uraki, Y., and Sano, Y. (1998). Preparation of carbon fibers from softwood lignin by atmospheric acetic acid pulping. Carbon N. Y. 36, 1119-1124. doi:10.1016/S0008-6223(98)00086-4

Kubo, S., Yoshida, T., and Kadla, J. F. (2007). Surface porosity of lignin/PP blend carbon fibers. J. Wood Chem. Technol 27, 257-271. doi:10.1080/02773810701702238

Lai, C., Zhou, Z., Zhang, L., Wang, X., Zhou, Q., Zhao, Y., et al. (2014a). Freestanding and mechanically flexible mats consisting of electrospun carbon nanofibers made from a natural product of alkali lignin as binder-free electrodes for high-performance supercapacitors. J. Power Sources 247, 134-141. doi:10.1016/j.jpowsour.2013.08.082

Lai, C., Kolla, P., Zhao, Y., Fong, H., and Smirnova, A. L. (2014b). Lignin-derived electrospun carbon nanofiber mats with supercritically deposited Ag nanoparticles for oxygen reduction reaction in alkaline fuel cells. Electrochim. Acta 130, 431-438. doi:10.1016/j.electacta.2014.03.006

Lallave, M., Bedia, J., Ruiz-Rosas, R., Rodriguez-Mirasol, J., Cordero, T., Otero, J. C., et al. (2007). Filled and hollow carbon nanofibers by coaxial electrospinning of alcell lignin without binder polymers. Adv. Mater. 19, 4292-4296. doi:10.1002/adma.200700963

Laurichesse, S., and Avèrous, L. (2014). Chemical modification of lignins: towards biobased polymers. Prog. Polym. Sci.39, 1266-1290. doi:10.1016/j.progpolymsci. 2013.11.004

Leitten, C., Griffith, W., Compere, A., and Shaffer, J. (2002). High-Volume, LowCost Precursors for Carbon Fiber Production. SAE Technical Paper 2002-01-1907. doi10.4271/2002-01-1907

Li, X.-F., Xu, Q., Fu, Y., and Guo, Q.-X. (2014). Preparation and characterization of activated carbon from Kraft lignin via $\mathrm{KOH}$ activation. Environ. Prog. Sust. Energy 33, 519-526. doi:10.1002/ep.11794

Li, X.-F., Zuo, Y., Zhang, Y., Fu, Y., and Guo, Q.-X. (2013). In situ preparation of $\mathrm{K}_{2} \mathrm{CO}_{3}$ supported Kraft lignin activated carbon as solid base catalyst for biodiesel production. Fuel 113, 435-442. doi:10.1016/j.fuel.2013.06.0

Lin, J., Kubo, S., Yamada, T., Koda, K., and Uraki, Y. (2012). Chemical thermostabilization for the preparation of carbon fibers from softwood lignin. Bioresources 7, 5634-5646. doi:10.15376/biores.7.4.5634-5646

Lin, L., Li, Y., and Ko, F. K. (2013). Fabrication and properties of lignin based carbon nanofiber. J. Fiber Bioeng. Informat. 6, 335-347. doi:10.3993/jfbi12201301

Lora, J. (2008). "Industrial commercial lignins: sources, properties and applications," in Monomers, Polymers and Composites from Renewable Resources, eds M. N. Belgacem and A. Gandini (Amsterdam: Elsevier BV), 225-241. 
Loscertales, I. G., Barrero, A., Guerrero, I., Cortijo, R., Márquez, M., and GañanCalvo, A. M. (2002). Micro/nano encapsulation via electrified coaxial liquid jets. Science 295, 1695-1698. doi:10.1126/science.1067595

Loscertales, I. G., Barrero, A., Márquez, M., Spretz, R., Velarde-Ortiz, R., and Larsen, G. (2004). Electrically forced coaxial nanojets for one-step hollow nanofiber design. J. Am. Chem. Soc. 126, 5376-5377. doi:10.1021/ja049443j

Luo, J., Genco, J., Cole, B. J. W., and Fort, R. C. (2011). Lignin recovered from the near-neutral hemicellulose extraction process as a precursor for carbon fiber. Bioresources 6, 4566-4593.

Maldhure, A. V., and Ekhe, J. D. (2011). Preparation and characterizations of microwave assisted activated carbons from industrial waste lignin for $\mathrm{Cu}$ (II) sorption. Chem. Eng. J. 168, 1103-1111. doi:10.1016/j.cej.2011.01.091

Mansmann, M. (1974). Stable Lignin Fibers. GB 1359764 A.

McCarthy, J. L., and Islam, A. (2000). "Lignin chemistry, technology, and utilization: a brief history," in Lignin: Historical, Biological, and Materials Perspectives, ACS Symposium Series, Vol. 742, eds W. G. Glasser, R. A. Northey, and T. P. Schultz (Washington, DC: American Chemical Society), 2-99. doi:10.1021/bk2000-0742.ch001

Mikawa, S. (1970). Lignin-based carbon fiber. Chem. Econ. Eng. Rev. 2, 43-46.

Montane, D., Torne-Fernandez, V., and Fierro, V. (2005). Activated carbons from lignin: kinetic modeling of the pyrolysis of Kraft lignin activated with phosphoric acid. Chem. Eng. J. 106, 1-12. doi:10.1016/j.cej.2004.11.001

Montero, G. A., Peresin, M. S., and Rojas, O. J. (2008). "Lignins in the production of nanofibers via elecrospinning," in The Abstract Book of The 82nd ACS Colloid and Surface Science Symposium.

Nordström, Y., Norberg, I., Sjoholm, E., and Drougge, R. (2012). A new softening agent for melt spinning of softwood Kraft lignin. J. Appl. Polym. Sci. 129, 1274-1279. doi:10.1002/APP.38795

Otani, S., Fukuoka, Y., Igarashi, B., and Sasaki, K. (1969). Method For Producing Carbonized Lignin Fiber. US 3461082 A.

Qing, S., Zhang, T., Zhang, W.-X., Chen, S., and Mezgebe, M. (2011). Lignin-based activated carbon fibers and controllable pore size and properties. J. Appl. Polym. Sci. 121, 989-994. doi:10.1002/app.33701

Radovic, L. R., and Rodríguez-Reinoso, F. (1997). in Chemistry and Physics of Carbon, Vol. 25, ed. P. A. Thrower (New York, NY: Marcel Dekker), 243-358.

Ragauskas, A. J., Beckham, G. T., Biddy, M. J., Chandra, R., Chen, F., Davis, M. F., et al. (2014). Lignin valorization: improving lignin processing in the biorefinery. Science 344, 1246843. doi:10.1126/science.1246843

Rodríguez-Mirasol, J., Bedia, J., Cordero, T., and Rodríguez, J. J. (2005). Influence of water vapor on the adsorption of VOCs on lignin-based activated carbons. Sep. Sci. Technol. 40, 3113-3135. doi:10.1080/01496390500385277

Rodríguez-Mirasol, J., Cordero, T., and Rodríguez, J. J. (1993a). Preparation and characterization of activated carbons from eucalyptus Kraft-lignin. Carbon N. Y. 31, 87-95. doi:10.1016/0008-6223(93)90160-C

Rodríguez-Mirasol, J., Cordero, T., and Rodriguez, J. J. (1993b). Activated carbons from $\mathrm{CO}_{2}$ partial gasification of eucalyptus Kraft lignin. Energy Fuels 7, 133-138. doi:10.1021/ef00037a021

Rodríguez-Mirasol, J., Cordero, T., and Rodriguez, J. J. (1996). High temperature carbons from lignin. Carbon N. Y. 34, 43-52. doi:10.1016/0008-6223(95)00133-6

Rosas, J. M., Bedia, J., Rodríguez-Mirasol, J., and Cordero, T. (2008). Preparation of hemp-derived activated carbon monoliths. Adsorption of water vapour. Ind. Eng. Chem. Res. 47, 1288-1296. doi:10.1021/ie070924w

Rosas, J. M., Bedia, J., Rodríguez-Mirasol, J., and Cordero, T. (2009). Hemp-derived activated carbon fibers by chemical activation with phosphoric acid. Fuel 88 19-26. doi:10.1016/j.fuel.2008.08.004

Rosas, J. M., Bedia, J., Rodríguez-Mirasol, J., and Cordero, T. (2010). On the preparation and characterization of chars and activated carbons from orange skin. Fuel Proc. Technol. 91, 1345-1354. doi:10.1016/j.fuproc.2010.05.006

Rosas, J. M., Ruiz-Rosas, R., Rodríguez-Mirasol, J., and Cordero, T. (2012). Kinetic study of the oxidation resistance of phosphorus-containing activated carbons. Carbon N. Y. 50, 1523-1537. doi:10.1016/j.carbon.2011.11.030

Ruiz-Rosas, R., Bedia, J., Lallave, M., Loscertales, I. G., Barrero, A., RodriguezMirasol, J., et al. (2010). The production of submicron diameter carbon fibers by the electrospinning of lignin. Carbon N. Y. 48, 696-705. doi:10.1016/j.carbon. 2009.10.014

Ruiz-Rosas, R., Valero-Romero, M. J., Salinas-Torres, D., Rodríguez-Mirasol, J., Cordero, T., Morallón, E., et al. (2014). Electrochemical performance of hierarchical porous carbon materials obtained from the infiltration of lignin into zeolite templates. ChemSusChem 7, 1458-1467. doi:10.1002/cssc.201301408
Saha, D., EWarren, K. E., and Naskar, K. (2014a). A. Soft-templated mesoporous carbons as potential materials for oral drug delivery. Carbon N. Y. 71, 47-57. doi:10.1016/j.carbon.2014.01.005

Saha, D., Warren, K. E., and Naskar, K. (2014b). Controlled release of antipyrine from mesoporous carbons. Microporous Mesoporus Mater. 196, 327-334. doi:10. 1016/j.micromeso.2014.05.024

Sen, S., Sadeghifar, H., and Argyropoulos, D. S. (2013). Kraft lignin chain extension chemistry via propargylation, oxidative coupling, and Claisen rearrangement. Biomacromolecules 14, 3399-3408. doi:10.1021/bm4010172

Seo, D. K., Jeun, J. P., Kim, H. B., and Kang, P. H. (2011). Preparation and characterization of the carbon nanofiber mat produced from electrospun PAN/lignin precursors by electron beam irradiation. Rev. Adv. Mater. Sci. 28, 31-34.

Seydibeyoglu, M. O. (2012). A novel partially biobased PAN-lignin blend as a potential carbon fiber precursor. J. Biomed. Biotechnol. 2012, 598324. doi:10.1155/ 2012/598324

Sharma, R. K., Wooten, J. B., Baliga, V. L., Lin, X., Chan, W. G., and Hajaligol, M. R. (2004). Characterisation of chars from pyrolysis of lignin. Fuel 83, 1469-1482. doi:10.1016/j.fuel.2003.11.015

Shen, Q., Zhang, T., Zhang, W.-X., Chen, S., and Mezgebe, M. (2011). Lignin-based activated carbon fibers and controllable pore size and properties. J. Appl. Polym. Sci. 121, 989-994. doi:10.1002/app.33701

Smolarski, N. (2012). High-Value Opportunities for Lignin: Unlocking its Potential. Paris: Frost \& Sullivan, 15.

Smook, G. A. (2002). Handbook for Pulp and Paper Technologies, 3rd Edn. Vancouver, BC: Angus Wilde Publications Inc.

Sudo, K., and Shimizu, K. (1987). Production of Lignin-Based Carbon Fiber. JP 62110922.

Sudo, K., and Shimizu, K. (1992). A new carbon fiber from lignin. J. Appl. Polym. Sci. 44, 127-134. doi:10.1002/app.1992.070440113

Sudo, K., and Shimizu, K. (1994). Method for Manufacturing Lignin for Carbon Fiber Spinning. US 5344921 A.

Sudo, K., Shimizu, K., Nakashima, N., and Yokoyama, A. (1993). A new modification method of exploded lignin for the preparation of a carbon fiber precursor. J. Appl. Polym. Sci. 48, 1485-1491. doi:10.1002/app.1993.070480817

Suhas, Carrott, P. J. M., and Ribeiro Carrott, M. M. L. (2007). Lignin - from natural adsorbent to activated carbon: a review. Biores. Technol 98, 2301-2312. doi:10.1016/j.biortech.2006.08.008

Sun, Y., Yang, G., Zhang, J.-P., Wang, Y., and Yao, M. S. (2012). Activated carbon preparation from lignin by $\mathrm{H}_{3} \mathrm{PO}_{4}$ activation and its application to gas separation. Chem. Eng. Technol. 35, 309-316. doi:10.1002/ceat.201100309

Teng, N.-Y., Dallmeyer, I., and Kadla, J. F. (2013). Incorporation of multiwalled carbon nanotubes into electrospun softwood Kraft lignin-based fibers. J. Wood Chem. Technol. 33, 299-316. doi:10.1080/02773813.2013.795807

Tenhaeff, W. E., Rios, O., More, K., and McGuire, M. A. (2014). Highly robust lithium ion battery anodes from lignin: an abundant, renewable, and low-cost material. Adv. Funct. Mat. 24, 86-94. doi:10.1002/adfm.201301420

Thunga, M., Chen, K., Grewell, D., and Kessler, M. R. (2014). Bio-renewable precursor fibers from lignin/polylactide blends for conversion to carbon fibers. Carbon N. Y. 68, 159-166. doi:10.1016/j.carbon.2013.10.075

Tomani, P. (2010). The lignoboost process. Cellulose Chem. Technol. 44, 53-58.

Torné-Fernández, V., Mateo- Sanz, J. M., Montané, D., and Fierro, V. (2009). Statistical optimization of the synthesis of highly microporous carbons by chemical activation of Kraft lignin with NaOH. J. Chem. Eng. Data 54, 2216-2221. doi:10.1021/je800827n

Uraki, Y., Hubo, S., Nigo, N., Sano, Y., and Sasaya, T. (1995). Preparation of carbon fibers from organosolv lignin obtained by aqueous acetic acid pulping. Holzforschung 49, 343-350. doi:10.1515/hfsg.1995.49.4.343

Uraki, Y., Kubo, S., Kurakami, H., and Sano, Y. (1997). Activated carbon fibers from acetic acid lignin. Holzforschung 51, 188-192. doi:10.1515/hfsg.1997.51. 2.188

Uraki, Y., Nakatani, A., Kubo, S., and Sano, Y. (2001). Preparation of activated carbon fibers with large specific surface area from softwood acetic acid lignin. J. Wood Sci. 47, 465-469. doi:10.1007/BF00767899

Valero-Romero, M. J., Márquez-Franco, E. M., Bedia, J., Rodríguez-Mirasol, J., and Cordero, T. (2014). Hierarchical porous carbons by liquid phase impregnation of zeolite templates with lignin solution. Microporous Mesoporous Mater. 196, 68-78. doi:10.1016/j.micromeso.2014.04.055

Wang, S. X., Yang, L., Stubbs, L. P., Li, X., and He, C. (2013). Lignin-derived fused electrospun carbon fibrous mats as high performance anode materials for 
lithium ion batteries. ACS Appl. Mater. Interfaces 5, 12275-12282. doi:10.1021/ am4043867

Warren, C. D. (2008). "Future lower cost carbon fiber for autos: international scaleup \& what is needed," in 8th-Annual Automotive Composites Conference and Exhibition (ACCE 2008): The Road to Lightweight Performance (Troy: SPE Automotive and Composites Divisions), 50-108.

Wohlmann, B., Woelki, M., Ebert, A., Engelmann, G., and Fink, H.-P. (2010). Lignin Derivative, Shaped Body Comprising the Derivative, and Carbon Fibers Produced From the Shaped Body. WO 2010081775.

Wu, X., and Radovic, L. R. (2006). Inhibition of catalytic oxidation of carbon/carbon composites by phosphorus. Carbon N. Y. 44, 141-151. doi:10.1016/j.carbon.2005. 06.038

Xie, X., Goodell, B., Zhang, D., Nagle, D. C., Qiang, Y., Petersong, M. L., et al. (2009). Characterization of carbons derived from cellulose and lignin and their oxidative behavior. Biores. Technol. 100, 1797-1802. doi:10.1016/j.biortech.2008.09.057

Yawalata, D., and Paszner, L. (2004). Anionic effect in high concentration alcohol organosolv pulping. Holzforschung 58, 1-6. doi:10.1515/HF.2004.002
Conflict of Interest Statement: The authors declare that the research was conducted in the absence of any commercial or financial relationships that could be construed as a potential conflict of interest.

Received: 06 October 2014; accepted: 14 November 2014; published online: 04 December 2014.

Citation: Rosas JM, Berenguer R, Valero-Romero MJ, Rodríguez-Mirasol J and Cordero $T$ (2014) Preparation of different carbon materials by thermochemical conversion of lignin. Front. Mater. 1:29. doi: 10.3389/fmats.2014.00029

This article was submitted to Carbon-Based Materials, a section of the journal Frontiers in Materials.

Copyright $\odot 2014$ Rosas, Berenguer, Valero-Romero, Rodríguez-Mirasol and Cordero. This is an open-access article distributed under the terms of the Creative Commons Attribution License (CC BY). The use, distribution or reproduction in other forums is permitted, provided the original author(s) or licensor are credited and that the original publication in this journal is cited, in accordance with accepted academic practice. No use, distribution or reproduction is permitted which does not comply with these terms. 